IZADP No. 2946

Working Hours Flexibility and

Older Workers' Labor Supply

Anne C. Gielen

July 2007 


\title{
Working Hours Flexibility and Older Workers' Labor Supply
}

\author{
Anne C. Gielen \\ Tilburg University, CentER, \\ Institute for Labor Studies (OSA) and IZA
}

Discussion Paper No. 2946

July 2007

IZA

P.O. Box 7240

53072 Bonn

Germany

Phone: +49-228-3894-0

Fax: +49-228-3894-180

E-mail: iza@iza.org

\begin{abstract}
Any opinions expressed here are those of the author(s) and not those of the institute. Research disseminated by IZA may include views on policy, but the institute itself takes no institutional policy positions.

The Institute for the Study of Labor (IZA) in Bonn is a local and virtual international research center and a place of communication between science, politics and business. IZA is an independent nonprofit company supported by Deutsche Post World Net. The center is associated with the University of Bonn and offers a stimulating research environment through its research networks, research support, and visitors and doctoral programs. IZA engages in (i) original and internationally competitive research in all fields of labor economics, (ii) development of policy concepts, and (iii) dissemination of research results and concepts to the interested public.
\end{abstract}

IZA Discussion Papers often represent preliminary work and are circulated to encourage discussion. Citation of such a paper should account for its provisional character. A revised version may be available directly from the author. 


\section{ABSTRACT}

\section{Working Hours Flexibility and Older Workers' Labor Supply*}

This paper studies the presence of hours constraints on the UK labor market and its effect on older workers labor supply, both at the extensive and the intensive margin. Using panel data for the period 1991-2004, the results from a competing risks model show that over-employed male workers can freely reduce working hours with their current employer before retiring completely. However, some over-employed women are observed to leave the labor market early due to hours constraints. Despite the fact that more flexibility in hours may increase labor market participation of older women, this paper presents some explorative results which illustrate that increasing working hours flexibility does not seem to increase older workers total labor supply as has often been suggested.

JEL Classification: J22, J26, J63

Keywords: labor supply, hours constraint, mobility, retirement

Corresponding author:

Anne C. Gielen

Department of Economics

Tilburg University

P.O. Box 90153

NL-5000 LE Tilburg

The Netherlands

E-mail: a.c.gielen@uvt.nl

\footnotetext{
* The author would like to thank Jan van Ours, Marcel Kerkhofs, Norma Coe, Trudie Schils, Mark Bryan, Alison Booth, Steve Pudney and Stephen Jenkins for helpful suggestions. The author gratefully acknowledges financial support from the Institute for Labor Studies (OSA), the European Centre for Analysis in the Social Sciences (ECASS) and from the Netherlands Organization for Scientific Research (NWO). In addition, the author thanks the Institute for Social and Economic Research (ISER), University of Essex, for its hospitality while this research was carried out.
} 


\section{Introduction}

As in many other OECD countries, the UK labor market is ageing. By 2050, the percentage of individuals aged 65 and older compared with the total working-age population (aged 20-64) will rise to 47 percent from 27 percent in 2003 (OECD (2004)). This may exert pressure on public finances and a potential shortage of labor resources. The effects of ageing on the labor market can be mitigated if the trend towards early labor market exit of older workers can be reversed. In order to understand how this can be achieved, this paper examines the labor supply decision and workplace restrictions that may limit either the intensive or extensive margins of older workers' labor supply.

A key assumption in the majority of labor supply theory is that workers can choose any number of working hours at a given wage. This implies that employers are indifferent to the number of hours their employees work. However, several studies have criticized this assumption using both theoretical arguments and empirical evidence. Several explanations can be given as to why the number of working hours is not only the choice of the worker, but may also be influenced by the employer. First, the firm may face fixed costs of employment, or costs associated with the coordination of activities of workers who work different numbers of hours (see Hamermesh (1987) for an overview), and as a result the worker may face a lower bound on weekly working hours. Second, hours constraints can also arise as features of lifetime employment contracts, in which the wage and the marginal productivity of the worker diverge. The existence of such contracts can be explained by implicit contract-insurance models, agency models and firm-specific human capital models (Kahn and Lang, 1992, 1995). Since wages in implicit contracts are fixed to insure workers against demand fluctuations, workers in such contracts prefer to work less hours at times when firms experience high demand, while preferring to work more in times of reduced demand. According to the agency theory, workers can be contracted in deferred payment schemes in order to deter worker malfeasance. Due to the difference between the specified wage and the workers' marginal productivity, in such contracts hours are constrained from below for junior workers and from above for senior workers. Alternatively, in models with specific human capital, contracts are specified in such a way as to 
decrease worker mobility in order to make specific human capital investments being worthwhile. In these contracts, hours are constrained from above for junior workers and from below for senior workers. Finally, hours constraints can arise in the absence of perfect competition. If firms are monopsony hires of labor, they will negotiate a contract with relatively high working hours and low wages. Then, workers may want to work less hours at the given wage (Naylor (2003)). Such a situation may also arise if labor mobility is costly or if better alternative employment opportunities are scarce. On the other hand, if workers have monopoly power, e.g. due to union power, then the resulting contract may be characterized by relatively few hours and high wages, and each individual worker may want to work more hours.

Recently, several studies have found empirical evidence of working hours constraints. Restrictions on working hours have been found for the UK, where 40 percent of all employed workers prefer to work a different number of hours and the majority of them would like to reduce working hours (Stewart and Swaffield (1997); Boheim and Taylor (2004); Bryan (2007)). Hours constraints have also been found in other countries, such as the US (Altonji and Paxson (1986, 1988, 1992), Charles and DeCicca (2007)), Germany (Wolf (1998)), and the Netherlands (Euwals (2001)).

This paper focuses on the effects of hours constraints on the labor market position of older workers in the UK. As workers age, they may prefer to reduce their number of working hours, for example due to health constraints or care obligations. Consequently, one may expect to observe a gradual drop in working hours before full retirement. However, Figure 1 illustrates that such a gradual retirement process is not common in the UK: in general, a discrete drop in hours is observed at the time of retirement. The number of usual working hours per week drops by 5 hours for men in the years prior to retirement, while for women the drop is only 2 hours. This limited hours change may be explained by the institutional setting in the UK. First, the defined benefit occupational pensions (which covers about 54 percent of all employees; OECD (2004)) discourages gradual retirement, because the pension benefit depends on final salary (Meghir and Whitehouse (1997)). Second, until April 2006, there was a legal constraint on drawing a pension while continuing to work for the same employer. As a result, workers who belonged to an employer's pension in their existing job were less likely to shift into part- 
time work, but those who had a pension from a previous employer were actually three times more likely to work part-time before retirement than those who had never participated in an employer's pension scheme (Banks and Smith (2006)).

However, the retirement decision may also be affected by working hours constraints imposed by the employer. A lower bound on the number of working hours may discourage older workers from continuing to work longer, thereby resulting in a discrete drop in working hours where older workers retire, and fall from working full-time to not working at all. This might well be the case in the UK, where the proportion of older workers working more than 50 hours per week is much higher, on average, than in other OECD countries (OECD (2006)). These long hours may explain the large percentage of male workers who would like to work less hours and hence are denoted over-employed (Figure 1). Possibly, due to a larger hours adjustment for males than for females in the years preceding retirement, the proportion of over-employed women is increasing as they approach retirement, while this proportion is more or less constant among male workers (but remains at a higher level). The figure suggests that working hours flexibility may be effective in reducing the proportion of over-employment, thereby potentially reducing labor market exit. Using HRS data, Penner et al. (2002) conclude that among older American workers who left their job between 1992 and 2000 about 13\% would have stayed in their job if they could have reduced their number of working hours. In Sweden, about 7 percent of the workers aged 50 years and above claim to have physical problems which restrict them from continuing work in the present occupation until the official retirement age, but that shortening working hours would solve the problem (Wadensjö (2006)).

This paper examines how hours constraints affect the decision to continue working or to leave the labor market. Charles and DeCicca (2007) consider hours constraints in the US labor market and find that hours constrained workers' probability to retire is about 3 to 5 percentage points higher than that for unconstrained workers. However, it is quite likely that working hours constraints affect the retirement decision only if workers have no alternatives to changing working hours within the labor market. Using UK data, Boheim and Taylor (2004) take into account other adjustment possibilities, such as a job change or promotion. They find that workers are able to adjust working hours according to preferences, but this is 
greatly facilitated through within- and between-employer job changes. Additionally, they find that hours constraints positively affect the probability to leave the labor market. ${ }^{1}$ This paper focuses on older workers (aged 50 and older) in particular since older workers may have less opportunities to change jobs and can more easily exit the labor force than prime-age workers. These transitions out of the labor market are quite important, since in general older workers leaving the labor force are not very likely to return due to limited hiring of older workers (Gielen and van Ours (2006), OECD (2006)). This study contributes to the literature by investigating the effect of over-employment on older workers labor supply, looking at both the participation decision (i.e. extensive margin) and the total number of hours worked (i.e. intensive margin). A related study for the US by Gustman and Steinmeier (2004) has found that increasing working hours flexibility could lead to a significant extension of older workers' working lives, and that the net change in effective labor supply would be smaller but is still positive. ${ }^{2}$ However, the US labor market is quite distinct from the UK labor market in terms of labor market flexibility and social security provisions. Furthermore, especially in the UK, the issue of flexible working hours for older workers has received a lot of public attention, as it has been suggested as a policy instrument to increase older workers' labor force participation and to reduce the large drop in labor supply due to the early retirement of the baby boom generation (e.g. EFA (2001, 2002)). The results are used to predict to what extent working lives can be prolonged by increasing flexibility in working hours, and how this would affect total labor supply of older workers.

The structure of the paper is as follows. Section 2 presents a theoretical model about the labor market behavior of over-employed workers. The empirical model is presented in section 3. Section 4 describes the data and presents some stylized facts. In section 5 the results of the empirical analysis are presented, which illustrate that hours constraints may affect the labor participation decision of older workers if possibilities to adjust hours within the labor market are relatively limited. Section 6 focuses attention on the effects of increased working hours flexibility on total labor supply. Finally, section 7 provides a conclusion.

\footnotetext{
${ }^{1}$ Not necessarily retirement, since they focus on working-age individuals in general.

${ }^{2}$ Similar results have been found for Sweden by Wadensjö (2006), though this study uses information on the abolishment of a gradual retirement scheme, rather than increasing hours flexibility, combined with participation figures from the early 1980s, when early labor market exit of older workers was much more accepted than nowadays.
} 


\section{Theoretical model}

This section presents a simple life-cycle model which is based on Cremer et al. (2004) and Sheshinksi $(2006,2007)$. Although the empirical analysis in this paper is based on a reduced form specification, the model presented in this section serves to illustrate the labor supply decision of older workers when faced with working hours constraints. In this model, older workers are observed to participate in the labor market from age $50(t=0)$ until retirement at age $t=R$. The maximum lifespan is $T$. Workers' preferences at age $t$ can be represented by an additive separable utility function defined over consumption $(c)$ and the number of hours worked per week $(l):^{3}$

$$
U_{t}=u\left(c_{t}\right)-e_{t} v\left(l_{t}\right)
$$

where $u^{\prime}(c)>0, u^{\prime \prime}(c)<0, v^{\prime}(l)>0$ and $v^{\prime \prime}(l)>0$. The second term in equation (1) denotes the disutility of labor. The first component $\left(e_{t}\right)$ denotes the disutility associated with working until age $t$, which is assumed to be nondecreasing with age $\left(e_{t}^{\prime} \geq 0\right) .{ }^{4}$ The second component denotes disutility associated with the length of the workweek $(v(l))$. When time-preference and the interest rate are assumed to equal 0, lifetime utility $V$ equals

$$
V=\sum_{t=0}^{T} u\left(c_{t}\right)-\sum_{t=0}^{R} e_{t} v\left(l_{t}\right)
$$

Wages are assumed to be constant over time $\left(w=w_{t}\right)$. Then, the lifetime budget constraint equals

$$
\sum_{t=0}^{T} c_{t}=\sum_{t=0}^{R} w l_{t}
$$

which implies that total lifetime consumption equals total lifetime wage income. ${ }^{5}$

Maximizing lifetime utility (2) subject to the budget constraint (3) yields a constant optimal consumption level equal to

\footnotetext{
${ }^{3}$ Though slightly different from the prevailing life-cycle literature, this definition is useful when hours constraints are introduced. Furthermore, it distinguishes this dimension of labor supply from choosing the optimal retirement age $R$. Finally, a full-time work week is normalized to 1 , which implies that $0 \leq l \leq 1$.

${ }^{4}$ This disutility can be considered to be a discontinuous function at $l \rightarrow 0$ in order to provide an incentive to retire. Such a discontinuity may arise for example from start-up costs.

${ }^{5}$ This model assumes zero pensions after the age of retirement for computational simplicity. However, introducing a positive pension benefit would not change the predictions of the model.
} 


$$
c^{*}=\frac{\sum_{t=0}^{R} w l_{t}}{T}
$$

Hence, in this simplified model, the worker will set the level of consumption equal in all periods. ${ }^{6}$ The optimal number of weekly working hours is defined by

$$
u^{\prime}\left(c^{*}\right) w=e_{t} v^{\prime}\left(l_{t}^{*}\right)
$$

It is evident that workers will work more hours for a higher wage, and if the disutility of working at age $t$ is lower. If the disutility of work were to increase with age (e.g. due to health constraints) older workers would be expected to gradually reduce the number of hours worked until the age at which they retire from the labor market. In addition to the number of hours worked, labor supply of older workers is also determined by the age at which the worker decides to retire from the labor market. The optimum retirement age $\left(R^{*}\right)$ is defined by

$$
u^{\prime}\left(c^{*}\right) w l_{R^{*}}=e_{R^{*}} v\left(l_{R^{*}}\right)
$$

where the marginal benefits of postponing retirement by a small time period equal the marginal costs of such a postponement.

The optimal choice for consumption and work may be affected by the presence of hours constraints. Workers may face a lower bound on the number of weekly working hours. This constraint limits the number of hours worked to be at least $l^{c}$ :

$$
l_{t} \geq l^{c}
$$

Then, maximization of lifetime utility (2) subject to the budget constraint (3) and the hours constraint (7) yields a slightly different expression for $l$ :

$$
l_{t} \text { is defined by }\left\{\begin{array}{l}
u^{\prime}\left(c^{*}\right) w=e_{t} v^{\prime}\left(l_{t}^{*}\right) \text { if } l_{t}^{*} \geq l^{c} \\
u^{\prime}\left(c^{*}\right) w<e_{t} v^{\prime}\left(l^{c}\right) \text { if } l_{t}^{*}<l^{c}
\end{array}\right.
$$

\footnotetext{
${ }^{6}$ This results from the assumptions of time preference being equal to the interest rate, from the certain lifetime, and from the additive separability of the utility function.
} 
Workers for whom the constraint in (7) is not binding will work their optimal number of working hours $\left(l_{t}^{*}\right)$. However, workers for whom the constraint does bind will work more hours than they would prefer to. As a result, the marginal disutility of work is larger. This implies that at the initial optimal retirement age $R^{*}$ for a given level of consumption the marginal costs of a small postponement of retirement now exceed the marginal benefits. ${ }^{7}$ As a result, the worker could increase lifetime utility by lowering $R$, hence by choosing to retire earlier. The effects of the hours constraint on labor supply are illustrated by a graphical example in Figure $2 .{ }^{8}$ The top panel illustrates the (unconstrained) choice for the number of working hours $l$ at a given age $t$, which follows from equation (5). Since the disutility of working increases with age, the number of hours worked gradually declines when workers get older. The lower panel illustrates the retirement decision, where workers decide to retire as soon as the marginal costs of a small postponement of retirement (denoted by the marginal costs (MC) per hour worked, $\left.e_{t} v\left(l_{t}\right)\right) / l_{t}$ ) equal the marginal benefits of a small postponement of retirement (denoted by the marginal benefits (MB) per hour worked, $\left.u^{\prime}\left(c^{*}\right) w\right) .{ }^{9}$ Hence, workers work $l^{*}$ hours per week until they retire at age $R^{*}$. When workers face a lower bound on the number of working hours (denoted by $l^{c}$ ), marginal disutility of work increases. As a result, the marginal costs function in the lower panel rotates to the left, which causes the optimal retirement age to fall to $R^{c}$. The figure thus illustrates that hours constrained workers work more hours than they prefer for $R^{c}-t^{c}$ years, but retire $R^{*}-R^{c}$ years earlier than unconstrained workers. ${ }^{10}$ The net effect of hours constraints on total hours worked over the lifetime depends on whether the additional number of hours worked while being over-employed (area ABC) exceeds the number of hours lost due to early retirement (area CDEF).

\footnotetext{
${ }^{7}$ Note that $R^{*}$ refers to the optimal retirement age if the worker were to be unconstrained in his choice of $l$.

${ }^{8}$ The following functions are used in the simulation: $e_{t}=0.75 t^{\alpha}$ with $\alpha=0.8$, and $v\left(l_{t}\right)=1 /\left(1-l_{t}\right)^{2}$. For $u(c)$ no specific function is assumed, since the optimal level of consumption is constant over time.

${ }^{9}$ Note that from equation (4) and (6) it appears that the marginal benefit of each additional hour worked is constant, since $u^{\prime}\left(c^{*}\right) w$ is constant over time.

${ }^{10}$ Note that workers may decide to change jobs in order to lose the hours constraint. However, labor mobility is costly. Though the decision to change jobs is not being modelled here, one may argue that a worker may decide to change jobs as long as the mobility costs are smaller than the increase in disutility of labor imposed by the hours constraint.
} 
Overall, the message from the theoretical model is that hours constraints affect labor supply of older workers across two dimensions. First, workers are over-employed in that they work more hours than they would prefer for several periods. Second, hours constraints give rise to early retirement of workers. In the analysis below, an investigation is carried out into what extent empirical evidence for this can be found.

\section{Empirical model}

The first part of the empirical analysis considers the effect of working hours constraints on the labor market participation decision of older workers. The length of older workers' working lives is investigated by estimating the duration in employment after the age of 50 . Workers may leave the labor force either by retiring or by entering inactivity, which includes, for example, unemployment, disability, and other forms of inactivity. However, rather than leaving the labor force, over-employed workers may be able to reduce working hours with their current employer or by changing employers. Alternatively, workers may choose to change employers without reducing working hours if, for example, longer working hours are compensated for by a higher wage or fringe benefits, such that the utility of the new job exceeds the utility received from the current job. If workers have these options available to them, the desire to leave the labor force early may be reduced. Therefore, employment duration is modelled in a competing risks framework, where the transition of leaving the labor force is modelled, but where people can also make a transition within the labor market. Hence, a distinction is made between 5 separate destination states $m$, i.e. retirement, inactivity, hours reduction with the current employer, and changing employers with and without reducing working hours, where the former two are assumed to be absorbing states $^{11}$, while the latter three states are not. If workers change employers or reduce working hours with the current employer, they are continued to be observed in employment until they leave the labor force. Standard errors are corrected

\footnotetext{
${ }^{11}$ Continued employment in the current job without reducing working hours is defined as the reference state. Furthermore, re-entry is not modelled. Due to this restriction, the duration in the labor force is under-estimated, since 22 percent of the people who leave the labor force are observed to re-enter the labor market, either via unretirement ( $10 \%$ of all retirees) or by leaving inactivity ( $32 \%$ of all inactive people). In section 5 this issue is dealt with by applying several specifications for labor market exit.
} 
for observing multiple spells for some individuals by using the Huber Sandwich estimator (see Huber (1967) and White (1980)), which treats multiple spells for the same individual as being from the same cluster.

The model is estimated using a reduced-form approach, which provides a flexible dynamic structure to estimate the transition process. ${ }^{12}$ Even though survival occurs in continuous time, a discrete time competing risks model is estimated, because spell lengths are observed only in intervals. Since the data is subject to (exogenous) right censoring, an exit is not observed for each worker. ${ }^{13}$ Though these censored observations are included in the analysis, they provide no information for estimating the hazard rate. Furthermore, the data are subject to left truncation, which occurs when some of the spell starting dates are not observed. This causes a sample selection problem where the selection effect depends on survival time itself, since necessarily any individual whose employment spell ended before the age of 50 (and who did not return to employment before the age of 50) is excluded from the sample. In the analysis, left truncation is dealt with by modifying the density to reflect the fact that part of the population is systematically omitted from the sample (Wooldridge (2002)), i.e. by conditioning upon survival up to the truncation date (age of 50). ${ }^{14}$ Then, the discrete time hazard into one of the $m$ states is equal to the probability of making a transition in interval $t$, conditional upon survival up to the beginning of the interval. It is assumed that the conditional destination-specific hazard $h^{m}$ is independent of the other competing risks and can be derived from a latent variable model in which the error term has a standard logistic distribution, such that

$$
h_{i t}^{m}=\frac{\exp \left(\beta_{0}^{m}+\beta_{1}^{m} X_{i t}+\delta^{m} Z_{i t}+\theta_{t}^{m}\right)}{1+\sum_{m=1}^{5} \exp \left(\beta_{0}^{m}+\beta_{1}^{m} X_{i t}+\delta^{m} Z_{i t}+\theta_{t}^{m}\right)}
$$

\footnotetext{
${ }^{12}$ Alternatively, one may choose to estimate a dynamic programming model. However, the reduced-form approach is very useful for describing the actual data, without having to impose strong assumptions about functional form which are needed when using a dynamic programming approach.

${ }^{13}$ Attrition is assumed to be random, based on Buck et al. (2006), who show that the composition of the later cross-sections (wave 5 and wave 13) does not differ much from the composition of wave 1. Although Crouchley and Oskrochi (2001) conclude that attrition cannot be ignored, they add that information on a yearly basis (as in BHPS) is insufficient to identify the nature of the attrition process accurately, since much can happen in a year.

${ }^{14}$ Initial conditions are not explicitly modelled, though some attention will be paid to this in the next section.
} 
where $X_{i t}$ includes individual worker and job characteristics and $\delta^{m}$ measures the effect of overemployment $\left(Z_{i t}\right)$ on the exit probability to state $m$. The rate at which workers become overemployed is assumed to be independent of the process that drives worker mobility, conditional on individual characteristics. ${ }^{15}$ The baseline hazard $\left(\theta_{t}^{m}\right)$ is modelled using a piecewise constant specification. In this non-parametric approach, duration dependence is assumed to be constant within each interval $s$, but can be different across the intervals:

$$
\theta_{t}^{m}=\sum_{s}\left(\vartheta_{s}^{m} I_{s t}\right)
$$

Here, $I_{s t}$ are time-varying dummy variables to represent each time interval at risk. For males, eight time intervals are distinguished: 1 year, 2-3 years, 4-5 years, 6-7 years, 8-9 years, 10-11 years, 12-13 years, and 14-15 years. ${ }^{16}$ Note that these time intervals correspond to age intervals $51,52-53, \ldots, 63-64$. For women, only 6 time intervals are distinguished, where the last interval denotes a duration of 10 years (i.e. age 59). ${ }^{17}$ Since an intercept term is also estimated, $\vartheta_{1}^{m}$ is normalized to zero.

For the given hazard rate, the individual workers' likelihood contribution has the same form as the likelihood for a standard multinomial logit model (Allison (1982)): ${ }^{18}$

$$
L_{i}=\left[\prod_{m=1}^{5} h_{i t}^{m}\right]^{c_{t i}^{m}}\left[h_{i t}^{0}\right]^{1-\sum_{m=1}^{5} c_{t i}^{m}}\left[\prod_{\tau=1}^{t-1} h_{i \tau}^{0}\right]
$$

where

$$
h_{i t}^{0}=\frac{1}{1+\sum_{m=1}^{5} \exp \left(\beta_{0}^{m}+\beta_{1}^{m} X_{i t}+\delta^{m} Z_{i t}+\theta_{t}^{m}\right)} \quad \text { and } \quad c_{i t}^{m}=\left\{\begin{array}{ccc}
1 & \text { if } & c_{i t}=m \\
0 & \text { if } & c_{i t}=0
\end{array}\right.
$$

\footnotetext{
${ }^{15}$ This assumption is tested in section 5 .

${ }^{16}$ Two-years intervals are used because duration dependence could not be estimated for one-year intervals due to lack of data.

${ }^{17}$ Note that the normal retirement age is 65 for men and 60 for women during the sample period.

${ }^{18}$ Note that it is assumed here that the hazard is constant within each yearly interval. This assumption is needed since the observations are interval-censored over a period of a year.
} 
where $c^{m}$ is a destination-specific censoring indicator, which equals 1 if worker $i$ exits to state $m$ in interval $t$, and $h^{0}$ is the conditional probability of making no transition (reference category).

In order to account for unobserved components affecting the mobility decision, the model can be enriched by controlling for unobserved worker characteristics, which are modelled using a non-parametric mass points approach (Heckman and Singer (1984)). The unknown distribution of the unobserved heterogeneity term is approximated by a multivariate discrete distribution whose points of support, which can be interpreted as the (estimated) fixed effect for each group of individuals $(r)$ that shares a certain unobserved propensity (ceteris paribus) for making a certain transition, and the corresponding probabilities $\left(\pi_{r}\right)$, which is the probability that someone belongs to group $r$, are modelled by a multinomial logit specification and estimated jointly with the other parameters of the model. ${ }^{19}$ Then, the conditional hazard rate for individual $i$ who belongs to class $r$ in interval $t$ looks like this:

$$
h_{i t \mid r}^{m}=\frac{\exp \left(\beta_{0 r}^{m}+\beta_{1}^{m} X_{i t}+\delta^{m} Z_{i t}+\theta_{t}^{m}\right)}{1+\sum_{m=1}^{5} \exp \left(\beta_{0 r}^{m}+\beta_{1}^{m} X_{i t}+\delta^{m} Z_{i t}+\theta_{t}^{m}\right)}
$$

The likelihood contribution of individual $i$ in class $r$ is equal to:

$$
\mathcal{L}_{i}=\sum_{r=1}^{R} L_{i \mid r} \pi_{r} \quad \text { with } \quad \sum_{r=1}^{R} \pi_{r}=1
$$

Note that the inclusion of unobserved heterogeneity relaxes the assumpion of independent competing risks. Though the competing risks are still assumed to be independent conditional on both observable and unobservable heterogeneity, the hazard may include a common unobserved heterogeneity term which allows the unconditional risks to be correlated.

\footnotetext{
${ }^{19}$ In total, three points of support $(R=3)$ are included. The likelihood was not significantly improved when more mass points were added. Furthermore, the results are unlikely to be sensitive to the choice of a discrete distribution for unobserved heterogeneity (for example, as opposed to a continuous distribution), as discrete distributions have been shown to be sufficiently flexible to capture random effects unobserved heterogeneity (Van den Berg (2001)).
} 


\section{Data and stylized facts}

\subsection{Data}

In this paper data from the British Household Panel Survey (BHPS) is used for the period 1991$2004 .^{20}$ Initially, each year a representative sample of 10,000 individuals from 5,500 households was collected. As of 1999 households in Wales, Scotland and later Northern Ireland were added, which caused the yearly sample size to increase to approximately 16,000 individuals from 9,000 households. The dataset contains extensive information on both the individual and the household level, such as individual and spousal actual working hours, labor market position and transitions, and individual and household income characteristics.

The analysis focuses on workers between 50 and the statutory pension age (65 for males and 60 for females) who are employed at the age of 50. The age of 50 is chosen as the lower limit, since retirements are observed in the data as of the age of 50. Some individuals enter the survey after the age of 50. Using retrospective work-history information, one can determine whether someone was employed at the age of 50. However, 15 percent of the individuals are denoted as 'delayed entrant', since retrospective work-history information was missing or because they experienced non-employment spells between the age of 50 and the age at which they entered the survey. ${ }^{21}$ These delayed entrants are excluded from the analysis. Furthermore, employment spells extending beyond the statutory pension age are censored.

An important aspect for this study is the information the data provide about the worker's preference on working hours: 'Thinking about the hours you work, assuming that you would be paid the same amount per hour, would you prefer to work fewer hours (1), more hours (2), or continue with the same number of hours? (3).' Workers who report preferring to work less hours are defined as over-employed. Workers are denoted unconstrained if they prefer to continue to work the same number of hours. ${ }^{22}$ Furthermore, the data contains self-reported information about working hours satisfaction (scaled 1-7, ranging from 'not satisfied at all' (1)

\footnotetext{
${ }^{20}$ Unless otherwise indicated, the figures and tables in this paper are based on the BHPS data.

${ }^{21}$ Of all not-employed women aged 50 only 5 percent (re-)enters the labor market at a later age when they no longer need to take care of their children.

${ }^{22}$ People who prefer to work more hours are included in this group, since this occurs very rarely among older workers (about 4 percent of all workers).
} 
to 'completely satisfied' (7)). This information is used to indicate whether people prefer small or large working hours adjustments. Self-employed were excluded from the analysis, since they are expected to be more free to determine their number of working hours. Table 1 provides some sample means. Furthermore, the table illustrates the characteristics of over-employed workers compared to those of unconstrained workers. It appears that over-employment is associated with more hours of work and lower monthly non-labor income. Furthermore, over-employed workers are more often employed in temporary jobs. Finally, workers who are a member of an employer pension scheme are associated with more over-employment. Possibly, the defined benefit character of these schemes discourages gradual hours reductions.

\subsection{Stylized facts}

To illustrate the severity of being hours constrained, Table 2 presents a transition matrix. The table indicates that almost a quarter of over-employed male workers are able to become unconstrained in the following period with the current employer, possibly by means of an hours reduction. About 3 percent become unconstrained by changing employers. Hours constraints do not seem to affect the flow to retirement for males: the proportion of over-employed male workers that enter retirement is actually smaller than the proportion of unconstrained workers. However, the opposite is true for women. Over-employed female workers are more likely to retire than unconstrained women. This may be due to the fact that over-employed women are less likely than men to become unconstrained with their current employer and that they have to rely more on employer changes, which is rather difficult for older workers (see for example Gielen and van Ours (2006)).

Table 3 shows that hours reductions associated with employer changes are larger than those that occur with the current employer. This is suggestive evidence of hours constraints within jobs. When looking at the average age of exit, over-employed workers are found to retire one year earlier on average than unconstrained workers. This suggests that increased working hours flexibility may be associated with longer working lives of older workers.

In order to see whether over-employment indeed shortens working lives of older workers, the hazard rate to retirement is illustrated in Figure 3. For over-employed women, the hazard rate 
to retirement is higher than for other working females. This suggests that a lack of flexibility on the intensive margin may have an effect on labor supply at the extensive margin for women. This relationship does not appear to hold for males. The exit to inactivity is not used as an early exit by over-employed workers, according to Figure 4. Hence, over-employed seem to leave the labor force earlier only via retirement. Figures 5 to 7 show the hazard to withinemployment mobility. Over-employed women (and to a lesser extent also men) are more likely to reduce working hours either with the current employer or between employers. This suggests that workers do try to adjust hours within the labor market. If this is not possible, they may resort to retirement.

\section{Empirical results}

Since workers may either choose to adjust working hours inside the labor market or outside, a competing risks model is estimated, as described earlier. The transition model can be interpreted as a reduced form of an intertemporal utility comparison. The worker will choose the exit which yields him the highest lifetime utility. Hours reduction with the current employer is defined as a reduction in usual working hours excluding overtime hours. ${ }^{23}$ Table 4 presents the estimation results for the competing risks model for males. ${ }^{24}$ From the baseline model it appears that over-employed men are able to reduce working hours with their current employer. ${ }^{25}$ Possibly, this flexibility causes over-employment to have no effect on the hazard into retirement for males. Furthermore, the findings indicate that labor demand considerations play a role. The

\footnotetext{
${ }^{23}$ Additionally, paid overtime hours are not allowed to increase, so as to avoid having workers trading usual working hours for paid overtime hours. Furthermore, as part of a sensitivity analysis to correct for measurement error, usual hours are required to be reduced by at least 2 hours. The results remained unchanged.

${ }^{24}$ Labor market experience is excluded from the set of covariates (and is replaced by age and education level), since it would reduce the number of observations by one third. Moreover, the usual number of hours worked is excluded, since this may be endogenous. In order to correct for whether or not there is 'space' to adjust hours, a dummy variable for part-time work is included. However, results remain unchanged if these variables are included.

${ }^{25}$ Note that the effect of over-employment can only be identified properly when the 'no-anticipation' assumption holds (Abbring and Van den Berg (2003)). In this study it seems a reasonable assumption that anticipation effects cannot be of great significance, because shocks that affect the preference for working hours (such as health shocks or changes in labor market status of the spouse), and hence the probability to become over-employed appear rather unexpectedly. Furthermore, because of the data being collected over one-year intervals, the presence of anticipation shortly before the time the actual hours constraint arises would not bias the estimates as long as the anticipation occurs within the yearly interval.
} 
higher the local unemployment rate, the more likely older male workers are to enter inactivity. Overtime workers are less likely to reduce (usual) working hours with the current employer, possibly because they can reduce overtime hours as a means to respond to over-employment. If, on the other hand, overtime hours are part of the job, overtime workers are found to change employers to achieve a reduction in working hours. Moreover, workers are less likely to retire if their partner is also still employed. ${ }^{26}$ Institutions also matter. Workers who are a member of an employer pension scheme are more likely to retire completely and less likely to reduce working hours. This may be due to the defined benefit character of the occupational pension schemes. Finally, the baseline hazard to retirement shows a pattern of positive duration dependence, while for the other exits no particular pattern in duration dependence is found. The results for women are presented in Table 5. For over-employed women the opportunities to reduce working hours with the current employer seem to be rather limited, so they may have to rely on employer changes in order to reduce working hours. Possibly, since changing jobs can be very difficult for older workers, subsequent years of over-employment may cause the worker to reach the optimal number of lifetime labor supply, and therefore she may choose to retire. Furthermore, the higher the local unemployment rate, the more reluctant women are to change their current labor market position. Being in good health increases the probability of continued employment. In panel B of both tables, the analyses correct for unobserved heterogeneity by introducing three classes within which workers are related by a latent common factor. ${ }^{27}$ Unobserved heterogeneity is assumed to be perfectly correlated between the separate exits. A likelihood ratio (LR) test would indicate that including unobserved heterogeneity in the model significantly improves the model fit. ${ }^{28}$ Note however that a formal LR-test cannot be applied because one of the parameters is not identified in the model without unobserved heterogeneity. As panels A and B of Tables 4 and 5 illustrate, the results for over-employment

\footnotetext{
${ }^{26}$ There is a stream of literature which emphasizes that retirement is a joint decision of both the individual and the spouse due to complementarity of leisure (see for example Blau and Riphahn (1999) and Michaud (2003)). Since it is not the main purpose of this study to model joint decision making, only the single decision of the individual worker is considered, but the number of hours worked by the spouse is included as a regressor.

${ }^{27}$ Table A4.1 in the Appendix provides information on the size and characteristics of the separate classes.

${ }^{28}$ The model without unobserved heterogeneity is nested in the specification with unobserved heterogeneity and follows from the restriction that $\beta_{0 r}^{m}=\beta_{0 r^{\prime}}^{m}$ for all $r \neq r^{\prime}$.
} 
do not differ much from the baseline model. ${ }^{29}$

A potential problem with the previous results concerns the assumption that the incidence of over-employment is exogenous, while an endogenous selection mechanism may exist which causes individuals to experience over-employment. That is, the over-employment process may be affected by unobservable worker characteristics which also affect the hazard rate, e.g. workers with a high latent retirement probability may have already sorted into jobs with hours constraints. If such selectivity exists and is not taken into account, the causal effect of overemployment on leaving the labor market may be biased. To check whether there is an endogenous selection in the incidence of over-employment, the models in panel B are re-estimated where the estimated coefficients for over-employment are allowed to vary between the three unobserved heterogeneity classes. In this model, correlation between the unobserved characteristics and over-employment affects the estimation results and one would expect to find different coefficients for over-employment for each of the three classes. However, an LR-test indicates that the estimates for the different classes are not significantly different. Furthermore, the results remain more or less unchanged when correlation between the unobserved characteristics and being over-employed is controlled for along the lines of Mundlak (1978). Hence, this suggests that over-employment is unlikely to be endogenous. Unfortunately, the dataset provides no good instruments to account properly for selectivity.

Until now the analyses have only looked at the dummy variable indicating whether someone was over-employed or not. However, this dummy variable does not indicate whether workers prefer a large change in working hours or just a small one. If the preferred change in hours is rather small (say below a certain threshold level), people may decide not to respond to this at all. Therefore, in panels $\mathrm{C}$, information on hours satisfaction is included in the model. Here a dummy variable is included for workers who report being over-employed, but still report being satisfied with working hours, and a dummy for over-employed workers who are dissatisfied with working hours. ${ }^{30}$ The results indeed indicate that there may be some threshold level after

\footnotetext{
${ }^{29}$ Since the results appear to be very robust, both without unobserved heterogeneity and with perfectly correlated unobserved heterogeneity, imperfect correlation in unobserved heterogeneity is not modelled as it is unlikely to change the main results.

${ }^{30} \mathrm{An}$ LR-test indicates that the inclusion of these dummy variables significantly improves the model fit compared to the model in panel A for males, though for women it is only a marginal improvement.
} 
which people start to respond to being over-employed. Dissatisfied over-employed males are more likely to reduce working hours than workers who report being over-employed but still are satisfied with the number of working hours. Some dissatisfied over-employed women are able to reduce working hours with the employer, while others have to rely on changing employer as a means to reduce working hours. Since there may be costs associated to changing jobs, only women who prefer a large change in working hours may consider it worth the costs, while women who prefer only a small change may consider retirement as an attractive alternative. On the other hand, over-employment among women who are satisfied with their hours may also represent a preference for retirement. Again, the results do not change much when correcting for unobserved heterogeneity. ${ }^{31}$

In order to illustrate the magnitude of the over-employment effect, Table 6 presents some marginal effects. ${ }^{32}$ Male workers who are over-employed and dissatisfied with working hours only respond to over-employment by reducing hours with the current employer. In general, these workers have a 5 percentage points higher probability of reducing working hours with the current employer than unconstrained workers, though the effect is slightly smaller in the year before the official retirement age. This may be due to the effect of final wage on the pension benefit. Female workers who are dissatisfied with working hours respond to over-employment by changing employers rather than reducing hours with the current employer. Note that an hours-reducing employer change only occurs among women aged 50 to 54 . For older women near retirement changing employers may not pay off due to the costs associated with an employer change. The potential lack of hours adjustment possibilities for over-employed women may cause them to work more hours. Due to the disutility associated with work they may decide to leave the labor force early. As the table illustrates, over-employed women between ages 50 and 54 are more likely to enter inactivity, while possibilities for early retirement increase at later ages. ${ }^{33}$ Figure 8 presents the predicted survivor function, which indicates by how much

\footnotetext{
${ }^{31}$ Not presented in table; results are available from the author upon request.

${ }^{32}$ Marginal effects are evaluated at the mean of the covariates. For dummy variables, the marginal effect represents the partial effect from a discrete (0 to 1 ) change.

${ }^{33}$ Marginal effects for satisfied and dissatisfied over-employment on retirement are not significantly different for women.
} 
over-employment affects the timing of leaving the labor force. ${ }^{34} \mathrm{~A}$ distinction is made between survival functions for several (hypothetical) situations: for workers who are not over-employed at all during their working lives, and for workers who become over-employed at a certain age (while reporting dissatisfaction with working hours) and remain over-employed after that. ${ }^{35}$ As the figure clearly illustrates, there is no difference in the timing of exit between male workers who are over-employed and those that are not over-employed, while over-employed female workers seem to exit six months earlier than women who are not over-employed. While over-employed women start to leave the labor market on average at the age of 58 , women not over-employed leave one year later at the age of 59. ${ }^{36}$ This suggests that the working lives of women who leave the labor market early due to hours constraints can be prolonged by up to 12 months on average if hours flexibility were to be increased.

Tables 7 and 8 report several sensitivity analyses to check for initial conditions which may affect the relationship between over-employment and worker mobility. ${ }^{37}$ For example, some workers may have sorted themselves in part-time jobs already, as they are in the middle of the gradual retirement process. Since workers are expected to retire completely out of these so-called 'bridge jobs' ignoring this sorting could lead to the incorrect conclusion that hours inflexibility leads to retirement, while actually it reflects a preference for zero working hours. Hence, the model has been re-estimated for workers who were employed full-time (i.e. working at least 30 hours per week) at the time they are first observed in the sample. As the first estimation in panel A shows, the results remain mostly unchanged. Related to this is the question of whether the possibilities to adjust working hours depend on the number of hours worked in

\footnotetext{
${ }^{34}$ From the estimation results, predicted hazard rates are obtained, which can be used to predict survival functions.

${ }^{35}$ 'Hypothetical' since over-employment varies frequently over time. Only 25 percent of all workers who are over-employed at least once are over-employed for more than 3 successive years. On the other hand, about 40 percent of all workers are not over-employed at all during the observation period.

${ }^{36}$ These exit ages are relatively low since they also include the exit to inactivity. If only the exit to retirement is considered, it is found that men retire at the age of 63 , while unconstrained women retire at the age of 60 and over-employed women at 59. This is in line with Meadows (2003), who finds an average retirement age in the UK of 62.7 for men and 59.7 for women. Note that the average exit age is higher than was presented in Table 3, due to correction for censored cases in the empirical model. Since no exit age for individuals with only censored observations is observed, these were not included in the average presented in Table 3.

${ }^{37}$ Since the sensitivity results with and without unobserved heterogeneity are the same, only the results without correcting for unobserved heterogeneity are presented.
} 
the current contract. If working hours constraints are due to fixed costs of employment, some minimum level of working hours (e.g. threshold level) may exist below which an individual worker is no longer productive. It is obvious that individuals who work part-time are more likely to pass this threshold. The second estimation in panel A of Table 8 investigates whether hours constraints are more restrictive for women working part-time than for full-time workers. ${ }^{38}$ The results suggest that hours constraints are not the result of some minimum hours threshold, since actually women working part-time do respond to over-employment by reducing working hours with their current employer or by changing employers, while women working full-time are not observed to reduce hours in either way. This may reflect a difference between women in a career job versus any other job. Possibly, women working full-time are in their career job and are hesitant to look for bridge jobs since these may imply a job of lower quality. Lissenburgh and Smeaton (2003) have found that older women are successful in finding flexible jobs, but often these jobs are of inferior quality (while men end up in relatively good flexible jobs). Since women in their career job are likely to have accumulated savings and pension entitlements, these women may choose to leave the labor market altogether rather than to take up part-time employment in a low-quality job. A second type of sensitivity analysis addresses the issue of re-entry. As was mentioned earlier, the previous estimations did not allow for re-entry. However, the data illustrate that 22 percent of all workers who leave the labor force are observed to re-enter some time later. In panel B, retirement and inactivity are redefined to spells that last at least two years. This limits labor force re-entry to just 0.3 percent of the sample. As shown in panel B, the main findings remain unchanged. Though some overemployed dissatisfied women are observed to reduce hours with the current employer now, the effects on retirement and inactivity remain. Hence, the single spell model does not seem to be too restrictive. Finally, there may be a relationship between tenure at age 50 (i.e. the truncation date) and being over-employed, which may affect the results. For example, highly mobile workers (i.e. with short tenure) may be more likely to be over-employed. In panel C, the model is re-estimated for workers with long tenure, 5 and 10 years respectively. Again, the results

\footnotetext{
${ }^{38}$ This distinction cannot be made for men due to a lack of men working part-time.
} 
are largely unchanged. ${ }^{39}$ Similarly, the results may be affected by an underlying relationship between labor market experience, over-employment and turnover, e.g. low experience workers may have some unobserved preferences for non-employment. Therefore, they may be more likely to consider themselves over-employed and this may therefore affect turnover. As panel $\mathrm{C}$ shows, the results are more or less unchanged. The results in Tables 7 and 8, and the few differences in characteristics between over-employed and not over-employed (Table 1), suggest that there is no need to model initial conditions separately and that it suffices to correct for selective sample selection due to left truncation, as was explained in section 3.

The results from Tables 4 and 5 suggest that some over-employed women in their career job may retire early, since they cannot adjust working hours as easily as men can. To check whether leaving the labor force was indeed an involuntary choice for these women, this paper investigates whether workers who have left the labor force are willing to take up a new job or not. ${ }^{40}$ In other words, if someone is really 'pushed' out of the labor market, she should still want to work after she has left the labor force. Table 9 provides the results from a probit model. It appears that labor market exit via inactivity is often less voluntary than exit via retirement, as workers who left to inactivity are more willing to take up a new job. For men, the over-employment status at the time of labor market exit does not affect the job search or the willingness to take up another job. This is in line with the results from Table 4, where it is found that over-employed men are able to reduce working hours with the current employer very easily. Hence, males that do retire probably do so because they prefer to leave the labor market. On the other hand, the finding is that women who were over-employed at the time of labor market exit are more likely to prefer a new job than women who were not over-employed at the time of exit. This suggests that unconstrained women deliberately choose to retire, while over-employed women were 'pushed' out of the labor market. ${ }^{41}$ Again, correcting for unobserved heterogeneity does not change the results. Furthermore, panel B illustrates that only over-employed women who

\footnotetext{
${ }^{39}$ In the last specification, several coefficients drop in significance, which may be due to a drop in the number of observations.

${ }^{40}$ Someone is defined as willing to take up a new job if they are either actively looking for paid work or if they are not looking right now but would like to have a paid job.

${ }^{41}$ Over-employment at the time of labor market exit increases the probability of preferring a new job by 10 percentage points.
} 
are dissatisfied with their working hours left to early retirement involuntarily. This illustrates the importance of using hours satisfaction measures when analyzing over-employment. If we were to use only a dummy for being over-employed, the prevalence of hours constraints would be over-estimated. Finally, panel $\mathrm{C}$ suggests that only dissatisfied women who are working full-time feel 'pushed' to leave the labor market early. This may be due to career concerns which causes women working full-time to be reluctant to accept lower quality jobs. Women working part-time, who may be less concerned with their career, adjust working hours (and change jobs) more easily and therefore experience no 'involuntary' labor market exit.

All in all, the results suggest that increasing working hours flexibility may prolong the working lives of older workers. In particular, increasing flexibility which allows gradual retirement via good-quality part-time jobs may be effective in increasing labor market participation among older women. The recent abolition of the legal constraint on drawing a pension while continuing to work with the same employer for workers with a defined benefit occupational pension system is likely to have contributed to more flexibility in working patterns, and as such may have positive effects on older workers' labor market participation. On the other hand, the defined benefit character of these pension schemes may restrict the positive effect on the length of working lives as workers may be reluctant to opt for a gradual retirement pattern (which is often associated with lower wages (Ghent et al. (2001))) if their pension benefit depends on final salary.

\section{Employment effects}

The previous results have shown that the working lives of older female workers may be prolonged if flexibility in working hours were to increase. In addition to the effects on labor supply at the extensive margin, it is interesting to see whether an increase in working hours flexibility would increase total labor supply of older workers over the working lives, i.e. in the intensive margin. Increasing hours flexibility may prolong the working lives of the individuals who have now left the labor force early due to over-employment. On the other hand, the labor supply of over-employed workers may decrease if they have the opportunity to reduce working hours. The net effect on total labor supply depends on the relative size of both effects. 
Unfortunately, the data provide no information on the preferred reduction in working hours. As a result, it is not possible to ascertain how many hours the over-employed would have worked if they could have reduced working hours gradually. This section attempts to estimate the effect of more flexibility in working hours on total labor supply in a rather explorative analysis by comparing hours worked by the over-employed with hours worked by unconstrained workers. ${ }^{42}$ Figure 9 illustrates the distribution of the total number of hours worked by workers as of age 50 until the time of labor market exit. ${ }^{43}$ The total number of working hours is the cumulated number of hours worked per year until the year in which the worker leaves the labor market. In order to study the relationship between over-employment and total labor supply, the figure distinguishes between workers who have experienced little or no spells of over-employment (i.e. less than 10 percent of their time in the labor market as of age 50) and workers who have experienced more periods of over-employment (more than 10 percent of the time). The figure shows that males work more hours on average in their working lives (as of age 50) than females do. Furthermore, it appears that over-employment is associated with a larger number of total hours worked for older workers, especially for women. ${ }^{44}$ This suggests that a shorter work life does not completely offset the additional number of hours worked by over-employed, therefore total labor supply is actually higher in the presence of hours constraints. In addition, the net effect of increased hours flexibility on labor supply may be negative due to the low number of over-employed who leave the labor market relative to the number of over-employed who continue to participate in paid employment. Each year only 4 percent of the female labor force retires, 43 percent of whom is over-employed, while 29 percent of the female labor force is overemployed but continues to participate in the labor market without reducing working hours. On average, women work 29 hours per week. When working hours flexibility is increased, total labor supply remains unaffected if the reduction in weekly working hours among over-employed women equals about 1.6 hours per week. ${ }^{45}$ However, the actual average reduction in weekly

\footnotetext{
${ }^{42}$ Note that the results may be subject to selection bias since workers in full-time contracts are more likely to be over-employed than individuals working part-time.

${ }^{43}$ More precisely, total lifetime labor supply is of interest. However, since workers are only followed from age 50 to retirement, the figure shows total labor supply in this period, rather than over the total working life.

${ }^{44}$ For males, the difference is not significantly different at a 5 percent level of significance.

${ }^{45}$ That is, 94.4 percent of over-employed women would reduce weekly working hours on average by 1.6 hours, while the remaining 5.6 percent now continues to participate in the labor market working 27.4 hours per week
} 
working hours observed among the over-employed who were successful in reducing their working hours was about 7 hours. Hence, total labor supply is expected to decrease when working hours become more flexible.

To examine the effect of over-employment on total 'lifetime' labor supply, the total number of hours worked after the age of 50 at the time of labor market exit is regressed on the time of being over-employed during this period (denoted as a fraction of the total period of labor market activity after the age of 50). ${ }^{46}$ The explorative results from Table 10 suggest that the total number of hours worked increases if labor market withdrawal is postponed by one year. Note that this effect is slightly larger for males as they are more likely to work full-time. Over-employment significantly increases the labor supply of older women; but this does not apply for men. This finding corresponds with the results from the competing risks model, which suggested that males could reduce working hours relatively easily. However, the previous estimates also indicated that over-employed women may choose to leave the labor market early. The question is therefore how over-employment affects total lifetime labor supply. In panel $\mathrm{B}$, the indicator for the age at which someone left the labor market is omitted from the set of regressors. The results indicate that over-employment increases labor supply for women, regardless of the timing of retirement. Note however that the coefficient is slightly smaller due to the negative correlation between being over-employed and the age of labor market exit. Finally, panel $\mathrm{C}$ illustrates that the positive effects on total labor supply particularly hold for over-employed women working full-time. ${ }^{47}$ Hence, the results suggest that the early labor market withdrawal of over-employed women does not entirely offset the additional number of hours worked while being active in the labor market. Though far from being conclusive, the results suggest that an increase in working hours flexibility is likely to have negative effects on older women's labor supply.

All in all, increasing working hours flexibility, which has often been suggested as an instrument for increasing older workers' labor force participation in the UK (e.g. EFA (2001, 2002)),

as well.

${ }^{46}$ This is a rather explorative analysis as the over-employment status is likely to be endogenous.

${ }^{47}$ Here over-employment is denoted in the share of total time worked in part-time and full-time jobs, respectively. 
may be effective to increase older workers' labor supply in the extensive margin, but probably not in the intensive margin. Increasing the state pension age, as has recently been announced (Van de Coevering et al. (2006)), may be more effective in increasing older workers labor supply. Note that caution in interpreting the results is required. It would be interesting to see how the results are affected if accurate information about the desired change in working hours were to be present. Furthermore, not all hours worked may be equally productive. Matched worker-firm data may shed more light on hours constraints, as it allows a comparison to be made of working hours and labor mobility for workers in the same firm, and it may provide information about the productivity of the hours worked. This is left for future research.

\section{Conclusions}

Faced with workforce ageing, most OECD countries have to deal with the challenge of reversing the trend of early labor market exit to prevent future labor shortages. Flexible working hours have been widely supported as an important policy instrument to increase older workers' labor supply, though little evidence exists concerning their efficacy. This paper examines how working hours constraints affect the decision to continue working or to leave the labor market for older workers in the UK. Using a competing risks framework, the results indicate that over-employed men can freely adjust working hours with their current employer. Over-employed older women, though, leave the labor market earlier due to a lack of gradual retirement opportunities with the current employer. This is especially true for women working full-time. Since women working part-time may be less concerned with a lower quality bridge job, they may be able to adjust hours more easily. These results suggest that more flexible working hours could prolong the working lives of older women. However, this paper provides some explorative evidence that total labor supply of older workers would actually be lower if hours were more flexible: the increase in labor supply due to prolonged work is cancelled out by a reduction in working hours of the over-employed workers. Hence flexibility in working hours does not seem to be a suitable instrument for dealing with the challenge of workforce ageing, as has often been suggested. Possibly, increasing the official retirement age as was recently suggested is more effective in increasing older workers' total labor supply. However, if the participation of older workers on 
the labor market is considered to be more important than their actual contribution in terms of working hours, e.g. due to positive effects on psychological well-being or social welfare, increasing possibilities for gradual retirement in good-quality jobs may be desirable. It is left for future research to quantify the effect of hours constraints on the total number of hours worked by older workers. 


\section{References}

Abbring, J. H. and G. J. Van den Berg (2003). The nonparametric identification of treatment effects in duration models. Econometrica 71(5), 1491-1517.

Allison, P. (1982). Discrete time methods for the analysis of event histories. In S. Leinhardt (Ed.), Sociological methodology. San Francisco: Jossey-Bass.

Altonji, J. and C. Paxson (1986). Job characteristics and hours of work. Research in Labor Economics 8(A), 1-55.

Altonji, J. and C. Paxson (1988). Labour supply preferences, hours constraints, and hours-wage trade-offs. Journal of Labor Economics 6(2), 254-276.

Altonji, J. and C. Paxson (1992). Labor supply, hours constraints, and job mobility. The Journal of Human Resources 27(2), 256-278.

Banks, J. and S. Smith (2006). Retirement in the UK. Oxford Review of Economic Policy 22(1), $40-56$.

Blau, D. M. and R. Riphahn (1999). Labor force transitions of older married couples in Germany. Labour Economics 6, 229-251.

Boheim, R. and M. Taylor (2004). Actual and preferred working hours. British Journal of Industrial Relations 42(1), 149-166.

Bryan, M. (2007). Free to choose? differences in the hours determination of constrained and unconstrained workers. Oxford Economic Papers 59(2), 226-252.

Buck, N., J. Burton, H. Laurie, P. Lynn, and S. Uhrig (2006). Quality profile: British household panel survey - version 2.0: Waves 1 to 13: 1991-2003. ISER report, Essex.

Charles, K. K. and P. DeCicca (2007). Hours flexibility and retirement. Economic Inquiry 45(2), 251-267. 
Cremer, H., J.-M. Lozachmeur, and P. Pestieau (2004). Social security, retirement age and optimal income taxation. Journal of Public Economics 88, 2259-2281.

Crouchley, R. and G. Oskrochi (2001). A random effects treatment of dropout in multi-spell multi-state labour market panel data of the bhps. Centre of Applied Statistics working paper 2001-02, Lancaster University, Lancaster.

EFA (Employers Forum on Age) (2001). Ageism, too costly to ignore. Ageism report/5-01, Department for Work and Pensions, UK.

EFA (Employers Forum on Age) (2002). Flexible retirement: A snapshot of large employers' initiatives. Technical report, Department for Work and Pensions, UK.

Euwals, R. (2001). Female labour supply, flexibility of working hours, and job mobility. The Economic Journal 111(May), C120-C134.

Ghent, L., S. Allen, and R. Clark (2001). The impact of a new phased retirement option on faculty retirement decisions. Research on Aging 23(6), 671-693.

Gielen, A. C. and J. C. van Ours (2006). Age-specific cyclical effects in job reallocation and labor mobility. Labour Economics 13(4), 493-504.

Gustman, A. and T. Steinmeier (2004). Minimum hours constraints, job requirements and retirement. NBER Working Paper 10876, Cambridge.

Hamermesh, D. (1987). The demand for labor in the long run. In O. Ashenfelter and R. Layard (Eds.), Handbook of Labor Economics, Volume 1, pp. 429-471. North-Holland: Elsevier.

Heckman, J. and B. Singer (1984). A method for minimising the impact of distributional assumptions in econometric models for duration data. Econometrica 52, 271-320.

Huber, P. (1967). The behavior of maximum likelihood estimates under nonstandard conditions. Proceedings of the Fifth Berkeley Symposium on Mathematical Statistics and Probability I, $221-233$. 
Kahn, S. and K. Lang (1992). Constraints on the choice of work hours, agency versus specific capital. Journal of Human resources 27, 661-678.

Kahn, S. and K. Lang (1995). The causes of hours constraints: evidence from Canada. Canadian Journal of Economics 28, 914-928.

Lissenburgh, S. and D. Smeaton (2003). Employment transitions of older workers: The role of flexible employment in maintaining labor market participation and promoting job quality. Transitions after 50 series. Bristol: The Policy Press.

Meadows, P. (2003). Retirement ages in the UK: A review of the literature. Employment Relations Research Series 18, Department for Trade and Industry, UK.

Meghir, C. and E. Whitehouse (1997). Labour market transitions and retirement of men in the UK. Journal of Econometrics 79, 327-354.

Michaud, P. (2003). Joint labour supply dynamics of older couples. IZA Discussion Paper 832, Bonn.

Mundlak, Y. (1978). On the pooling of time series and cross section data. Econometrica $46(1)$, 69-85.

Naylor, R. (2003). Labor supply, efficient bargains and countervailing power. In M. Waterson (Ed.), Competition, monopoly and corporate governance: Essays in honour of Keith Cowling, pp. 101-116. Cheltenham: Edward Elgar publishing.

OECD (2004). United Kingdom. Ageing and employment policies. Paris: OECD.

OECD (2006). Live longer, work longer. Ageing and employment policies. Paris: OECD.

Penner, R., P. Perun, and E. Steuerle (2002). Legal and institutional impediments to partial retirement and part-time work by older workers. Urban institute research report, The Urban Institute, Washington DC.

Sheshinski, E. (2006). Note on longevity and aggregate savings. Scandinavian Journal of Economics 108(2), 353-356. 
Sheshinski, E. (2007). Longevity and aggregate savings. mimeo, The Hebrew University of Jerusalem, Jerusalem.

Stewart, M. and J. Swaffield (1997). Constraints on the desired hours of work of british men. The Economic Journal 107(March), 520-535.

Van de Coevering, C., D. Foster, P. Haunit, C. Kennedy, S. Meagher, and J. Van de Berg (2006). Estimating economic and social welfare impacts of pension reform. Pensions technical working paper, Department for Work and Pensions.

Van den Berg, G. (2001). Duration models: Specification, identification, and multiple durations. In J. J. Heckman and E. Leamer (Eds.), Handbook of Econometrics, Volume 5, pp. 3381-3460. Amsterdam: Elsevier.

Wadensjö, E. (2006). Part-time pensions and part-time work in sweden. IZA Discussion paper series 2273, Bonn.

White, H. (1980). A heteroskedasticity-consistent covariance matrix estimator and a direct test for heteroskedasticity. Econometrica 48, 817-838.

Wolf, E. (1998). Do hours restrictions matter? A discrete family labor supply model with endogenous wages and hours restrictions. Centre for European Research (ZEW) Discussion Paper 98-44, Mannheim.

Wooldridge, J. M. (2002). Econometric analysis of cross section and panel data. Cambridge: MIT Press. 
Table 1: Table of means

\begin{tabular}{l|ccc|ccc}
\hline & \multicolumn{3}{|c|}{ Males } & \multicolumn{3}{c}{ Females } \\
& O & U & All & O & U & All \\
\hline Over-employment (\%) & 100.0 & 0.0 & 43.0 & 100.0 & 0.0 & 36.4 \\
Weekly working hours & 40.7 & 38.6 & 39.5 & 35.3 & 25.3 & 29.0 \\
Age & 54.9 & 55.0 & 55.0 & 53.5 & 53.8 & 53.7 \\
Local unemployment rate (\%) & 5.4 & 5.6 & 5.5 & 5.0 & 5.7 & 5.4 \\
Married (\%) & 90.3 & 88.1 & 89.1 & 80.0 & 81.3 & 80.8 \\
Spousal working hours & 17.0 & 17.3 & 17.2 & 19.9 & 17.0 & 18.1 \\
Tenure (years) & 12.3 & 11.8 & 12.0 & 10.8 & 10.9 & 10.9 \\
Gross hourly wage & 10.1 & 9.9 & 10.0 & 8.2 & 6.3 & 7.0 \\
Gross monthly non-labor income & 106.1 & 117.9 & 112.8 & 65.5 & 84.2 & 77.4 \\
Temporary job (\%) & 43.1 & 40.7 & 41.7 & 46.7 & 40.5 & 42.8 \\
Working overtime (\%) & 54.2 & 50.6 & 52.1 & 41.6 & 32.0 & 35.6 \\
Job satisfaction (1-7) & 5.0 & 5.5 & 5.3 & 5.2 & 5.9 & 5.6 \\
Employer pension scheme (\%) & & & & & & \\
Member & & & & & & \\
Not a member & 74.7 & 70.5 & 72.3 & 66.6 & 43.8 & 52.1 \\
No scheme offered & 9.8 & 9.9 & 9.9 & 12.9 & 19.1 & 16.9 \\
& 15.5 & 19.6 & 17.8 & 20.5 & 37.1 & 31.0 \\
Education level (\%) & & & & & & \\
No qualification & & & & & & \\
Lower qualification & 26.7 & 29.6 & 28.3 & 22.0 & 35.0 & 30.2 \\
Medium qualification & 9.3 & 7.0 & 8.0 & 8.9 & 9.1 & 9.0 \\
High qualification & 20.1 & 23.6 & 22.1 & 32.1 & 32.7 & 32.5 \\
Health (\%) & 43.9 & 39.8 & 41.6 & 37.0 & 23.2 & 28.3 \\
Poor & & & & & & \\
Fair & & & & & & \\
Good & 3.5 & 3.7 & 3.6 & 5.3 & 5.4 & 5.4 \\
N & 21.5 & 16.5 & 18.7 & 19.2 & 17.1 & 17.8 \\
& 75.0 & 79.8 & 77.7 & 75.5 & 77.5 & 76.8 \\
\hline & 2149 & 2832 & 4981 & 1820 & 3109 & 4929 \\
\hline
\end{tabular}

Note: 'O' refers to over-employed workers; 'U' refers to unconstrained workers. 
Table 2: Transition matrix of being hours constrained (\%)

\begin{tabular}{|c|c|c|c|c|c|c|}
\hline \multirow[b]{3}{*}{$\begin{array}{l}\text { Hours constrained } \\
\text { at } \mathrm{t}\end{array}$} & \multicolumn{4}{|c|}{ Hours constrained at $t+1$} & \multicolumn{2}{|c|}{ Leave labor force } \\
\hline & \multicolumn{2}{|c|}{ Unconstrained } & \multicolumn{2}{|c|}{ Over-employed } & \multirow[b]{2}{*}{ Retired } & \multirow[b]{2}{*}{ Inactivity } \\
\hline & $\begin{array}{c}\text { Same } \\
\text { employer }\end{array}$ & $\begin{array}{c}\text { Employer } \\
\text { change }\end{array}$ & $\begin{array}{c}\text { Same } \\
\text { employer }\end{array}$ & $\begin{array}{l}\text { Employer } \\
\text { change }\end{array}$ & & \\
\hline \multicolumn{7}{|l|}{ A. Males } \\
\hline Over-employed & 23.0 & 3.4 & 54.5 & 4.9 & 4.4 & 2.8 \\
\hline Unconstrained & 57.2 & 6.7 & 18.6 & 2.1 & 4.9 & 2.7 \\
\hline \multicolumn{7}{|l|}{ B. Females } \\
\hline Over-employed & 19.0 & 4.3 & 57.5 & 4.4 & 4.5 & 2.5 \\
\hline Unconstrained & 64.9 & 5.2 & 13.1 & 1.4 & 3.0 & 3.3 \\
\hline
\end{tabular}

Note: Row percentages; sum is not 100 percent, since hours constraints in the next period are unobserved for workers who are no longer observed in the survey the next period. Retirement refers to the first time people report being retired, whereas inactivity refers to the first time people report being unemployed, disabled or otherwise inactive. Chi-squared tests for independence indicate that the hours constraints at $t+1$ for under-employed workers at $t$ are significantly different at the $1 \%$ level from those of over-employed workers at $t$. 
Table 3: Hours change and age of labor force withdrawal

\begin{tabular}{|c|c|c|c|c|c|c|}
\hline & \multicolumn{4}{|c|}{ Change in working hours } & \multicolumn{2}{|c|}{ Exit age } \\
\hline & \multirow[t]{2}{*}{ Stay } & \multirow{2}{*}{$\begin{array}{c}\text { Hours reduction } \\
\text { with employer }\end{array}$} & \multicolumn{2}{|c|}{ Employer change: } & \multirow[t]{2}{*}{ Retired } & \multirow[t]{2}{*}{ Inactivity } \\
\hline & & & Fewer hours & Same/more hours & & \\
\hline A. Males & & & & & & \\
\hline Over-employed & 0.5 & -5.5 & -6.4 & 0.2 & 59 & 55 \\
\hline Unconstrained & 0.6 & -4.9 & -5.1 & 2.5 & 60 & 55 \\
\hline $\mathrm{N}$ & 3468 & 675 & 199 & 279 & 215 & 145 \\
\hline B. Females & & & & & & \\
\hline Over-employed & 0.2 & -6.2 & -6.8 & 0.6 & 56 & 54 \\
\hline Unconstrained & 0.7 & -4.3 & -6.5 & 2.1 & 57 & 53 \\
\hline $\mathrm{N}$ & 3557 & 666 & 177 & 233 & 163 & 133 \\
\hline
\end{tabular}

Note: Retirement refers to the first time people report being retired, whereas inactivity refers to the first time people report being unemployed, disabled or otherwise inactive. 
Table 4: Competing risks model - Males

\begin{tabular}{|c|c|c|c|c|c|}
\hline & \multirow[b]{2}{*}{ Retirement } & \multirow[b]{2}{*}{ Inactivity } & \multirow{2}{*}{$\begin{array}{c}\text { Hours } \\
\text { reduction } \\
\text { with empl. }\end{array}$} & \multicolumn{2}{|c|}{ Employer change: } \\
\hline & & & & $\begin{array}{c}\text { less } \\
\text { hours }\end{array}$ & $\begin{array}{c}\text { same } / \text { more } \\
\text { hours }\end{array}$ \\
\hline \multicolumn{6}{|c|}{ A. Baseline model $(\log \mathrm{L}=-4653.382)$} \\
\hline Over-employment & $-0.027(0.164)$ & $-0.051(0.189)$ & $0.263(0.088) * *$ & $0.058(0.150)$ & $-0.263(0.139) *$ \\
\hline Unemployment rate & $1.667(3.193)$ & $11.297(3.182) * *$ & $0.034(1.977)$ & $-6.920(3.290) * *$ & $1.298(3.090)$ \\
\hline Working overtime & $-0.314(0.149) * *$ & $-0.118(0.186)$ & $-0.504(0.092) * *$ & $0.757(0.169) * *$ & $-0.520(0.135) * *$ \\
\hline Work hours spouse & $-0.015(0.005) * *$ & $-0.005(0.006)$ & $0.002(0.003)$ & $-0.007(0.005)$ & $0.003(0.004)$ \\
\hline Gross hourly wage & $0.021(0.009) * *$ & $-0.033(0.035)$ & $-0.013(0.010)$ & $0.006(0.013)$ & $0.001(0.009)$ \\
\hline \multicolumn{6}{|c|}{ Employer pension scheme } \\
\hline Member & $1.077(0.282) * *$ & $-0.139(0.242)$ & $-0.007(0.131)$ & $-0.292(0.196)$ & $-0.246(0.166)$ \\
\hline $\begin{array}{l}\text { Not a member } \\
\text { Health }\end{array}$ & $-0.059(0.431)$ & $-0.549(0.390)$ & $-0.060(0.176)$ & $-0.409(0.295)$ & $-0.260(0.227)$ \\
\hline Poor health & $1.043(0.381) * *$ & $1.257(0.313) * *$ & $0.183(0.264)$ & $0.226(0.439)$ & $0.032(0.406)$ \\
\hline Good health & $-0.140(0.196)$ & $-0.503(0.206) * *$ & $-0.017(0.116)$ & $0.236(0.210)$ & $0.089(0.176)$ \\
\hline \multicolumn{6}{|l|}{ Baseline hazard } \\
\hline $51-52$ & $0.710(0.649)$ & $-0.097(0.342)$ & $-0.164(0.157)$ & $-0.425(0.241) *$ & $-0.062(0.242)$ \\
\hline $53-54$ & $1.141(0.644) *$ & $0.426(0.334)$ & $-0.015(0.156)$ & $-0.160(0.249)$ & $0.232(0.236)$ \\
\hline $55-56$ & $2.048(0.614) * *$ & $0.266(0.360)$ & $-0.067(0.167)$ & $-0.020(0.252)$ & $0.327(0.244)$ \\
\hline $57-58$ & $2.207(0.625) * *$ & $0.488(0.377)$ & $0.256(0.171)$ & $-0.346(0.310)$ & $0.391(0.280)$ \\
\hline $59-60$ & $3.334(0.612) * *$ & $0.427(0.394)$ & $0.201(0.190)$ & $-0.210(0.364)$ & $0.431(0.291)$ \\
\hline $61-62$ & $3.136(0.624) * *$ & $0.622(0.430)$ & $0.204(0.210)$ & $-0.104(0.401)$ & $0.199(0.370)$ \\
\hline $63-64$ & $4.876(0.619) * *$ & $-0.634(0.792)$ & $0.049(0.276)$ & $0.321(0.476)$ & $0.202(0.481)$ \\
\hline
\end{tabular}

B. Including unobserved heterogeneity $(\log \mathrm{L}=-4635.223)$

$\begin{array}{llllll}\text { Over-employment } & -0.007(0.166) & -0.078(0.203) & 0.270(0.092) * * & 0.050(0.154) & -0.291(0.146) * *\end{array}$ Intercept $(\mathrm{r}=1) \quad-3.846(0.846) * *-3.849(0.937) * *-1.257(0.372) * *-1.591(0.623) * *-0.664(0.549)$ Intercept $(\mathrm{r}=2) \quad-4.005(0.922) * *-10.004(1.961) * *-2.640(0.690) * *-6.228(3.975) \quad-3.065(2.176)$ Intercept $(\mathrm{r}=3) \quad-9.974(1.460) * *-2.776(1.036) * *-7.252(0.686) * *-1.137(0.657) * *-0.384(0.565)$

C. Including hours satisfaction information ( $\log \mathrm{L}=-4646.875)$

Over-employment:

$\begin{array}{llllll}\text { - Satisfied } & -0.047(0.188) & -0.120(0.235) & 0.138(0.107) & -0.055(0.190) & -0.345(0.183) *\end{array}$ $\begin{array}{llllll}\text { - Dissatisfied } & 0.014(0.237) & 0.037(0.245) & 0.411(0.111) * * & 0.166(0.180) & -0.173(0.176)\end{array}$

Note: Baseline estimations are based on 4,981 observations. The set of covariates include dummy variables for overemployment, part-time work, temporary job, overtime hours, marital status, duration dependence, union coverage, membership of employer pension scheme, job satisfaction indicators (pay, work itself and job security), education level, industry, occupation, firm size, and local unemployment rate, the number of hours worked by the spouse, tenure, real gross hourly wage, real gross monthly non-labor income, and health indicators. Standard errors are in parentheses, a $* * / *$ indicates that the coefficient is different from zero at a $5 \% / 10 \%$ level of significance. 
Table 5: Competing risks model - Females

\begin{tabular}{|c|c|c|c|c|c|}
\hline & \multirow[b]{2}{*}{ Retirement } & \multirow[b]{2}{*}{ Inactivity } & \multirow{2}{*}{$\begin{array}{c}\text { Hours } \\
\text { reduction } \\
\text { with empl. }\end{array}$} & \multicolumn{2}{|c|}{ Employer change: } \\
\hline & & & & $\begin{array}{c}\text { less } \\
\text { hours }\end{array}$ & $\begin{array}{c}\text { same/more } \\
\text { hours }\end{array}$ \\
\hline \multicolumn{6}{|c|}{ A. Baseline model $(\log \mathrm{L}=-4282.344)$} \\
\hline Over-employment & $0.467(0.195) * *$ & $0.270(0.207)$ & $0.035(0.100)$ & $0.305(0.172) *$ & $-0.081(0.153)$ \\
\hline Unemployment rate & $4.563(3.881)$ & $2.601(3.907)$ & $-4.571(1.875) * *$ & $-7.797(3.962) * *-$ & $-14.362(3.144) * *$ \\
\hline Working overtime & $-0.042(0.188)$ & $-0.430(0.226) *$ & $-0.289(0.104) * *$ & $0.709(0.172) * *$ & $-0.234(0.151)$ \\
\hline Work hours spouse & $-0.008(0.005) *$ & $0.004(0.004)$ & $-0.005(0.002) * *$ & $0.002(0.003)$ & $-0.002(0.003)$ \\
\hline Gross hourly wage & $-0.003(0.025)$ & $-0.107(0.041) * *$ & $-0.024(0.018)$ & $0.014(0.026)$ & $-0.004(0.019)$ \\
\hline \multicolumn{6}{|c|}{ Employer pension scheme } \\
\hline Member & $0.899(0.271) * *$ & $-0.451(0.275)$ & $-0.096(0.136)$ & $-0.714(0.224) * *$ & $-0.121(0.210)$ \\
\hline Not a member & $0.513(0.313)$ & $-0.439(0.276)$ & $-0.059(0.145)$ & $-0.722(0.263) * *$ & $-0.325(0.245)$ \\
\hline \multicolumn{6}{|l|}{ Health } \\
\hline Poor health & $0.441(0.344)$ & $1.207(0.302) * *$ & $0.342(0.229)$ & $0.142(0.408)$ & $0.327(0.362)$ \\
\hline Good health & $-0.415(0.216) *$ & $-0.482(0.218) * *$ & $0.177(0.118)$ & $-0.245(0.199)$ & $0.291(0.196)$ \\
\hline \multicolumn{6}{|l|}{ Baseline hazard } \\
\hline $51-52$ & $0.889(0.564)$ & $0.282(0.283)$ & $0.085(0.137)$ & $0.325(0.248)$ & $0.046(0.216)$ \\
\hline $53-54$ & $1.351(0.550) * *$ & $-0.006(0.311)$ & $0.011(0.141)$ & $0.422(0.240) *$ & $0.216(0.204)$ \\
\hline $55-56$ & $1.567(0.548) * *$ & $0.141(0.328)$ & $-0.117(0.156)$ & $0.248(0.277)$ & $0.240(0.232)$ \\
\hline $57-58$ & $2.199(0.545) * *$ & $0.162(0.364)$ & $-0.004(0.162)$ & $-0.110(0.360)$ & $-0.384(0.309)$ \\
\hline 59 & $4.382(0.542) * *$ & $-0.014(0.552)$ & $0.266(0.215)$ & $1.034(0.397) * *$ & $-0.532(0.570)$ \\
\hline \multicolumn{6}{|c|}{ B. Including unobserved heterogeneity $(\log \mathrm{L}=-4272.541)$} \\
\hline Over-employment & $0.564(0.265) * *$ & $0.254(0.213)$ & $0.016(0.102)$ & $0.303(0.177) *$ & $-0.069(0.157)$ \\
\hline Intercept $(\mathrm{r}=1)$ & $-2.551(1.207) * *$ & $-2.743(1.004) * *$ & $-1.438(0.407) * *$ & $-2.335(0.747) * *$ & $-0.314(0.835)$ \\
\hline Intercept $(\mathrm{r}=2)$ & $-8.898(2.016) * *$ & $-1.357(1.433)$ & $-1.420(0.536) * *$ & $-1.437(1.080)$ & $0.746(0.669)$ \\
\hline Intercept $(\mathrm{r}=3)$ & $-4.205(1.786) * *$ & $-4.171(3.697)$ & $-4.680(2.931)$ & $-2.680(1.361) *$ & $-0.051(0.712)$ \\
\hline \multicolumn{6}{|c|}{$\begin{array}{l}\text { C. Including hours satisfaction information }(\log \mathrm{L}=-4277.137) \\
\text { Over-employment: }\end{array}$} \\
\hline - Satisfied & $0.454(0.220) * *$ & $-0.051(0.282)$ & $-0.104(0.123)$ & $0.205(0.206)$ & $-0.069(0.181)$ \\
\hline - Dissatisfied & $0.493(0.260) *$ & $0.660(0.260) * *$ & $0.232(0.129) *$ & $0.435(0.215) * *$ & $-0.086(0.208)$ \\
\hline
\end{tabular}

Note: Baseline estimations are based on 4,929 observations. For included covariates, see footnote Table 4. Standard errors are in parentheses, a $* * / *$ indicates that the coefficient is different from zero at a $5 \% / 10 \%$ level of significance. 


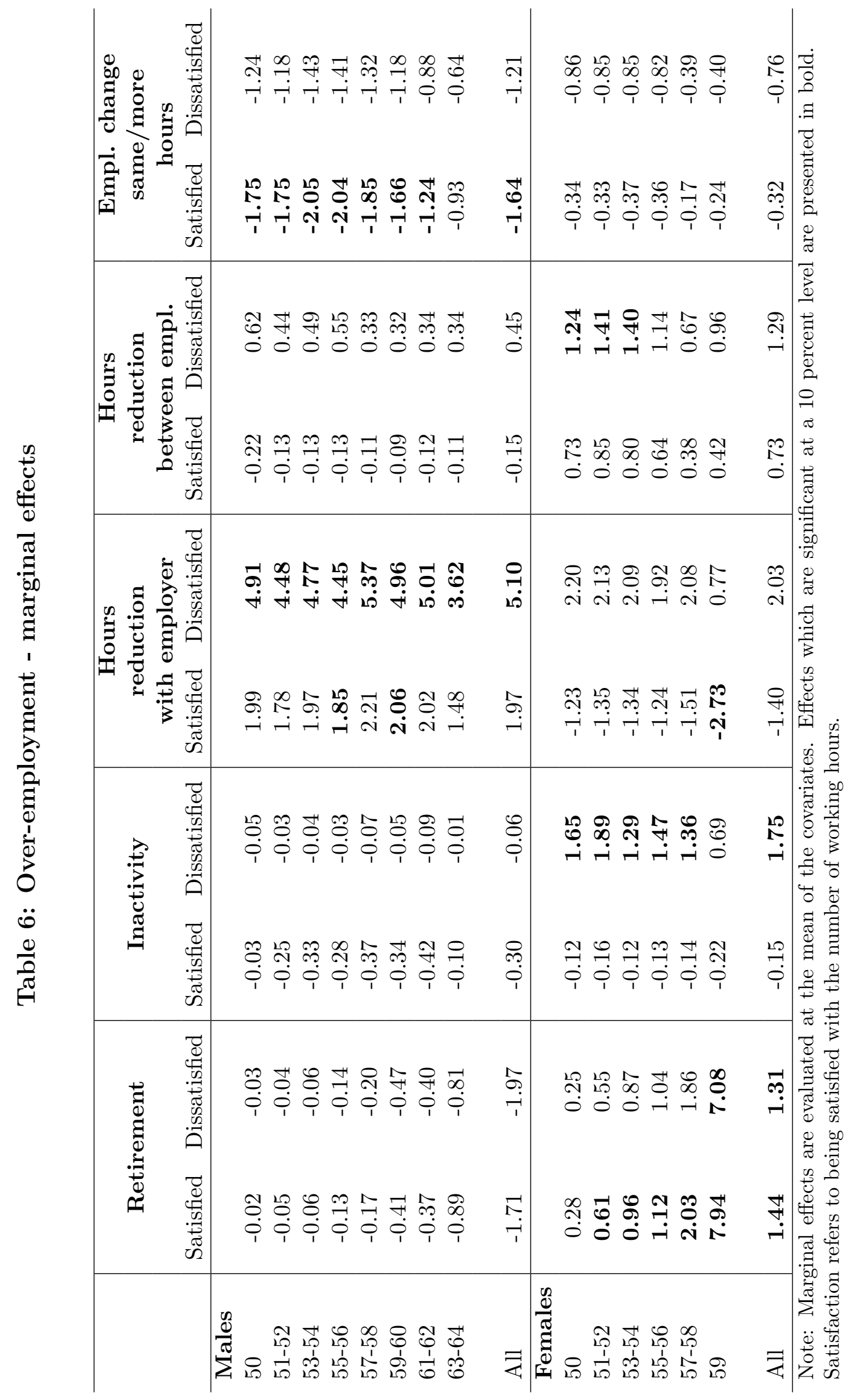


Table 7: Sensitivity analyses - Males

\begin{tabular}{ccccc}
\hline \multirow{2}{*}{ Retirement } & \multirow{2}{*}{ Inactivity } & Hours & \multicolumn{2}{c}{ Employer change: } \\
& & reduction & less & same/more \\
& with empl. & hours & hours \\
\hline
\end{tabular}

A. Working hours

Working full-time in first wave

Over-employment:

$\begin{array}{llllll}\text { - Satisfied } & -0.049(0.192) & -0.120(0.241) & 0.122(0.109) & -0.066(0.191) & -0.399(0.189) *\end{array}$

$\begin{array}{llllll}\text { - Dissatisfied } & -0.093(0.240) & 0.065(0.252) & 0.412(0.113) * * & 0.166(0.181) & -0.195(0.179)\end{array}$

B. Exclude exits to retirement and inactivity spells for shorter than 1 year

Over-employment:

$\begin{array}{llllll}\text { - Satisfied } & 0.032(0.198) & -0.245(0.328) & 0.120(0.103) & -0.064(0.183) & -0.319(0.148) * *\end{array}$

\begin{tabular}{llllll} 
- Dissatisfied & $0.166(0.250)$ & $-0.066(0.343)$ & $0.409(0.107) * *$ & $0.145(0.174)$ & $-0.234(0.149)$ \\
\hline
\end{tabular}

C. Long-tenure or -experience workers only

Tenure $\geq 5$ years

Over-employment:

- Satisfied $\quad-0.019(0.193) \quad-0.155(0.257)$

- Dissatisfied $0.025(0.245) \quad-0.117(0.285)$

$0.173(0.115) \quad-0.004(0.241) \quad-0.667(0.221) * *$

$0.458(0.121) * * \quad 0.330(0.221) \quad-0.364(0.220) *$

Tenure $\geq 10$ years

Over-employment:

$\begin{array}{lll}\text { - Satisfied } & -0.113(0.254) & 0.068(0.323)\end{array}$

$0.169(0.153) \quad 0.530(0.367) \quad-0.009(0.351)$

- Dissatisfied $\quad-0.093(0.312) \quad-0.331(0.386)$

$0.373(0.164) * * \quad 0.380(0.393)$

$0.544(0.342)$

Experience $\geq 30$ years

Over-employment:

$\begin{array}{llllll}\text { - Satisfied } & -0.035(0.188) & -0.122(0.239) & 0.135(0.110) & -0.079(0.198) & -0.359(0.187) *\end{array}$

$\begin{array}{llllll}\text { - Dissatisfied } & 0.037(0.240) & 0.091(0.248) & 0.395(0.117) * * & 0.215(0.189) & -0.273(0.188)\end{array}$

Note: Standard errors are in parentheses, a $* * *$ indicates that the coefficient is different from zero at a $5 \% / 10 \%$ level of significance. 
Table 8: Sensitivity analyses - Females

\begin{tabular}{lccccc}
\hline & Retirement & Inactivity & $\begin{array}{c}\text { Hours } \\
\text { reduction } \\
\text { with empl. }\end{array}$ & $\begin{array}{c}\text { Employer change: } \\
\text { less } \\
\text { hours }\end{array}$ & $\begin{array}{c}\text { same/more } \\
\text { hours }\end{array}$ \\
\hline & & & & & \\
A. Working hours & & & & & \\
$\begin{array}{l}\text { Working full-time in first wave } \\
\text { Over-employment: }\end{array}$ & & & & & \\
- Satisfied & $0.668(0.281) * *$ & $-0.093(0.383)$ & $-0.241(0.142) *$ & $0.140(0.237)$ & $-0.025(0.200)$ \\
- Dissatisfied & $0.484(0.328)$ & $0.966(0.355) * *$ & $0.152(0.145)$ & $0.383(0.250)$ & $-0.052(0.236)$ \\
& & & & & \\
Part-time vs. full-time & & & & & \\
Over-employment: & & & & & \\
- Satisfied - part & $0.602(0.379)$ & $0.414(0.380)$ & $0.480(0.213) * *$ & $-0.103(0.608)$ & $-0.052(0.424)$ \\
- Satisfied - full & $0.391(0.274)$ & $-0.301(0.383)$ & $-0.329(0.138) * *$ & $0.195(0.224)$ & $-0.109(0.200)$ \\
- Dissatisfied - part & $0.533(0.496)$ & $0.037(0.630)$ & $0.647(0.275) * *$ & $1.050(0.481) * *$ & $-0.498(0.644)$ \\
- Dissatisfied - full & $0.475(0.306)$ & $0.796(0.304) * *$ & $0.091(0.139)$ & $0.293(0.234)$ & $-0.080(0.211)$ \\
\hline
\end{tabular}

B. Exclude exits to retirement and inactivity spells for shorter than 1 year Over-employment:

$\begin{array}{llllll}\text { - Satisfied } & 0.440(0.229) * & -0.069(0.347) & -0.101(0.122) & 0.270(0.202) & -0.081(0.162)\end{array}$

$\begin{array}{llllll}\text { - Dissatisfied } & 0.095(0.311) & 0.639(0.323) * * & 0.272(0.127) * * & 0.486(0.210) * * & 0.183(0.177)\end{array}$

\section{Long-tenure or -experience workers only}

Tenure $\geq 5$ years

Over-employment:

- Satisfied

$0.352(0.239) \quad 0.021(0.337) \quad-0.146(0.133)$

$0.458(0.256) *-0.058(0.240)$

- Dissatisfied

$0.494(0.284) * \quad 0.950(0.299) * * \quad 0.120(0.140)$

$0.334(0.275) \quad 0.142(0.266)$

Tenure $\geq 10$ years

Over-employment:

- Satisfied

$0.282(0.301) \quad 0.648(0.427) \quad-0.149(0.171)$

$0.403(0.362) \quad-0.176(0.494)$

- Dissatisfied

$0.612(0.347) *$

$1.374(0.513) * * \quad 0.280(0.177)$

$0.034(0.445)$

$0.728(0.422) *$

Experience $\geq 30$ years

Over-employment:

- Satisfied

$0.346(0.285) \quad 0.108(0.372) \quad-0.047(0.153)$

$0.183(0.252)$

$0.040(0.234)$

- Dissatisfied

$0.718(0.321) * * \quad 0.751(0.397) * \quad 0.225(0.182)$

$0.150(0.284) \quad-0.037(0.285)$

Note: Standard errors are in parentheses, a $* * / *$ indicates that the coefficient is different from zero at a $5 \% / 10 \%$ level of significance. 
Table 9: Probit results job search of inactive individuals

\begin{tabular}{|c|c|c|c|c|}
\hline & \multicolumn{2}{|c|}{ Excluding u.h. } & \multicolumn{2}{|c|}{ Including u.h. } \\
\hline & Males & Females & Males & Females \\
\hline $\begin{array}{l}\text { A. Baseline model } \\
\text { Over-employed at exit } \\
\text { Exit to inactivity }\end{array}$ & $\begin{array}{l}0.054(0.125) \\
0.948(0.142) * *\end{array}$ & $\begin{array}{l}0.358(0.157) * * \\
1.022(0.190) * *\end{array}$ & $\begin{array}{r}-0.007(0.189) \\
1.627(0.229) * *\end{array}$ & $\begin{array}{l}0.410(0.242) * \\
1.742(0.298) * *\end{array}$ \\
\hline $\begin{array}{l}\text { B. Including hours s } \\
\text { Over-employed at exit: } \\
\text { - Satisfied } \\
\text { - Dissatisfied } \\
\text { Exit to inactivity }\end{array}$ & $\begin{array}{l}\text { tisfaction infor } \\
0.066(0.147) \\
-0.046(0.171) \\
0.934(0.141) * *\end{array}$ & $\begin{array}{l}0.075(0.189) \\
0.573(0.200) * * \\
0.986(0.188) * * \\
\end{array}$ & $\begin{array}{r}0.053(0.233) \\
-0.174(0.243) \\
1.644(0.228) * * \\
\end{array}$ & $\begin{array}{r}-0.027(0.324) \\
0.790(0.294) * * \\
1.708(0.300) \text { ** }\end{array}$ \\
\hline $\begin{array}{l}\text { C. Part-time vs. full } \\
\text { Over-employed at exit: } \\
\text { - Satisfied - part } \\
\text { - Satisfied - full } \\
\text { - Dissatisfied - part } \\
\text { - Dissatisfied - full } \\
\text { Exit to inactivity }\end{array}$ & $\begin{array}{l}- \\
- \\
- \\
-\end{array}$ & $\begin{array}{l}0.061(0.313) \\
0.084(0.207) \\
0.090(0.296) \\
0.676(0.227) * * \\
0.973(0.186) * *\end{array}$ & $\begin{array}{l}- \\
- \\
- \\
-\end{array}$ & $\begin{array}{r}-0.312(0.525) \\
0.126(0.382) \\
-0.009(0.650) \\
0.956(0.317) * * \\
1.694(0.299) * *\end{array}$ \\
\hline
\end{tabular}

Note: All estimations include a dummy for exit to inactivity, dummies for marital status and employment status of the spouse, age of labor market exit, duration out of employment, health measures, age, gross monthly non-labor income, education level, local unemployment rate and an indicator for over-employment status at the time of labor market exit. Standard errors are in parentheses, a **/* indicates that the coefficient is different from zero at a $5 \% / 10 \%$ level of significance. 
Table 10: Total number of hours worked

\begin{tabular}{ccccc}
\hline Workers choosing for: & \multicolumn{2}{c}{ Retirement } & \multicolumn{2}{c}{ Labor market withdrawal } \\
& Males & Females & Males & Females \\
& $(1)$ & $(2)$ & $(3)$ & $(4)$
\end{tabular}

\footnotetext{
A. Including exit age

Fraction of time

in over-employment

Age of labor market exit

$-0.086(0.316)$
$1.980(0.046) * *$

$2.541(0.475) * *$

$0.209(0.215)$

$2.426(0.305) * *$

$1.496(0.072) * *$

$1.972(0.031) * *$

$1.431(0.046) * *$

\section{B. Excluding exit age}

Fraction of time

in over-employment $\quad-0.583(0.926) \quad 1.432(0.855) * \quad 0.283(0.708) \quad 2.164(0.595) * *$

\section{Part-time vs. full-time}

Fraction of time

in over-employment:

- In part-time jobs

- In full-time jobs

$$
\begin{aligned}
& -0.275(1.276) \\
& 1.897(0.829) * *
\end{aligned}
$$

$0.552(0.854)$

$2.921(0.571) * *$ Note: The dependent variable is the total number of hours worked, from age 50 to the age of labor market
withdrawal, divided by 1000 . Labor market withdrawal includes exits to both retirement and inactivity.
All estimations include an indicator for the share of total working years someone has been over-employed,
a gender dummy, education level, health status, indicator for being a member of an employer pension
scheme, and an indicator for the number of years for which yearly working hours were not observed but
the individual was still active on the labor market. Standard errors are in parentheses, a $* * / *$ indicates
that the coefficient is different from zero at a $5 \% / 10 \%$ level of significance.
} 
Figure 1: Average usual working hours per week and the proportion of over-employed workers prior to retirement

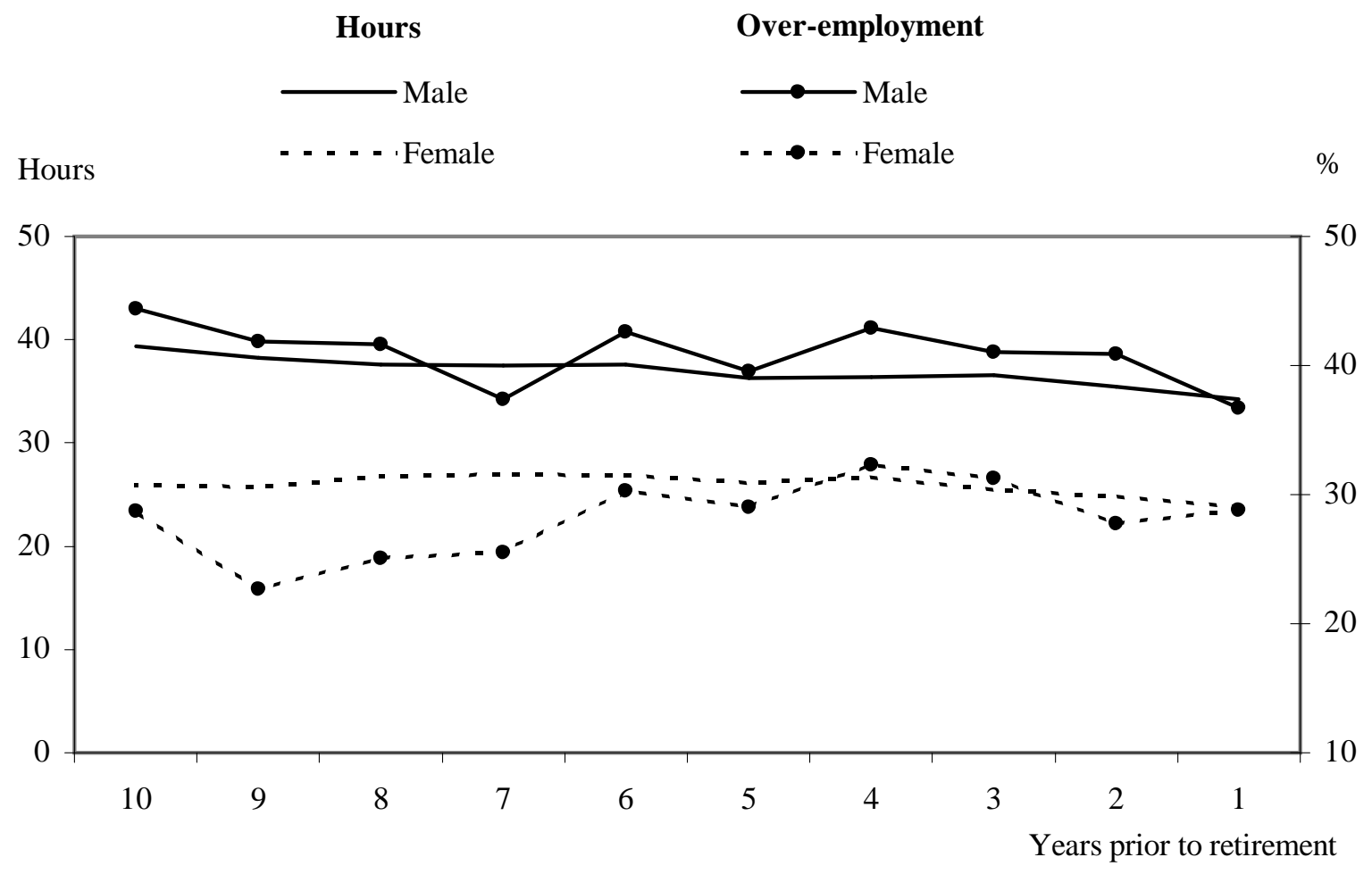

Note: Working hours exclude overtime hours. Retirement is defined as the first time workers report to be retired. 
Figure 2: Optimal labor supply - weekly working hours and retirement age

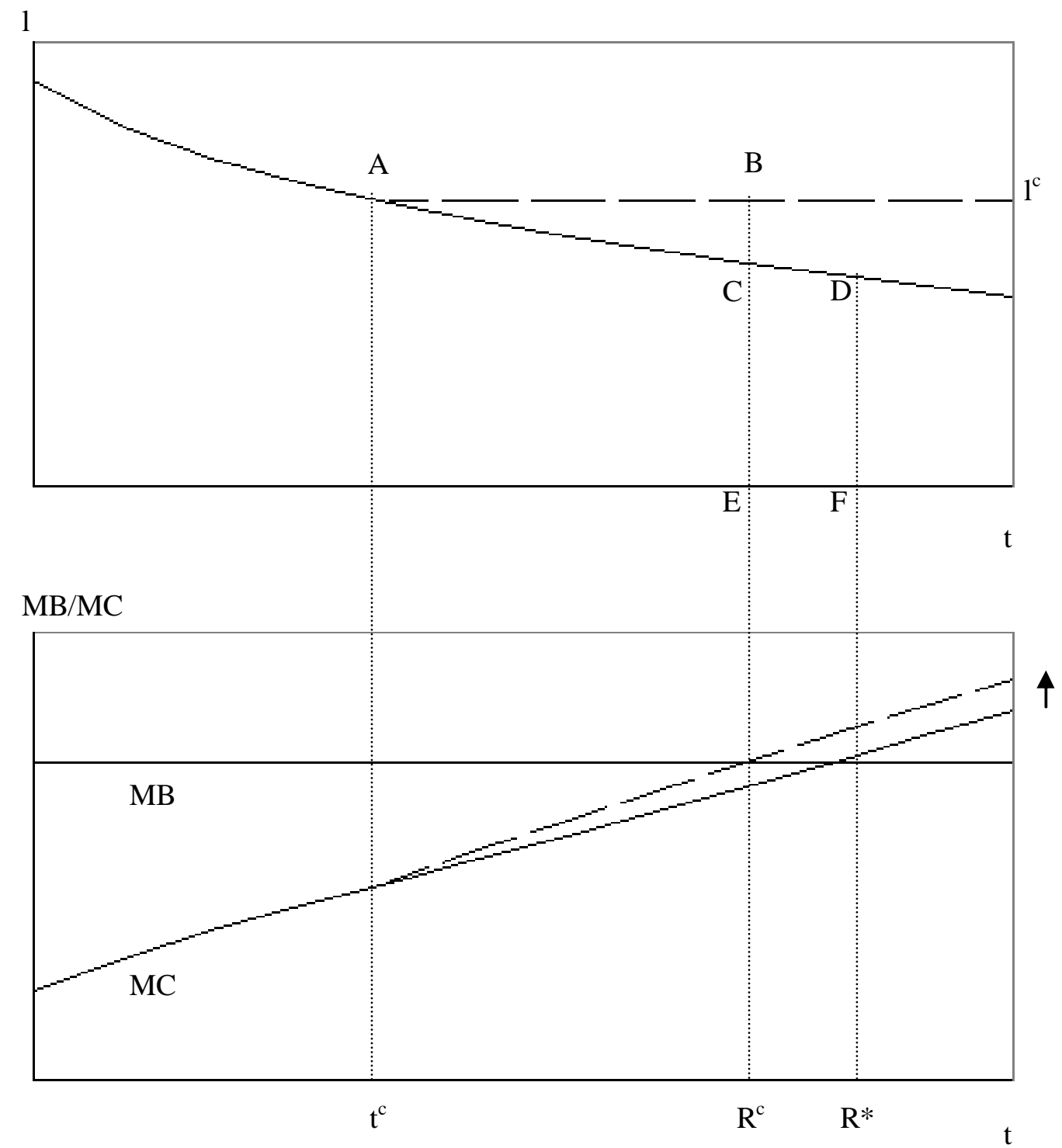


Figure 3: Hazard rate to retirement

$\%$

Males

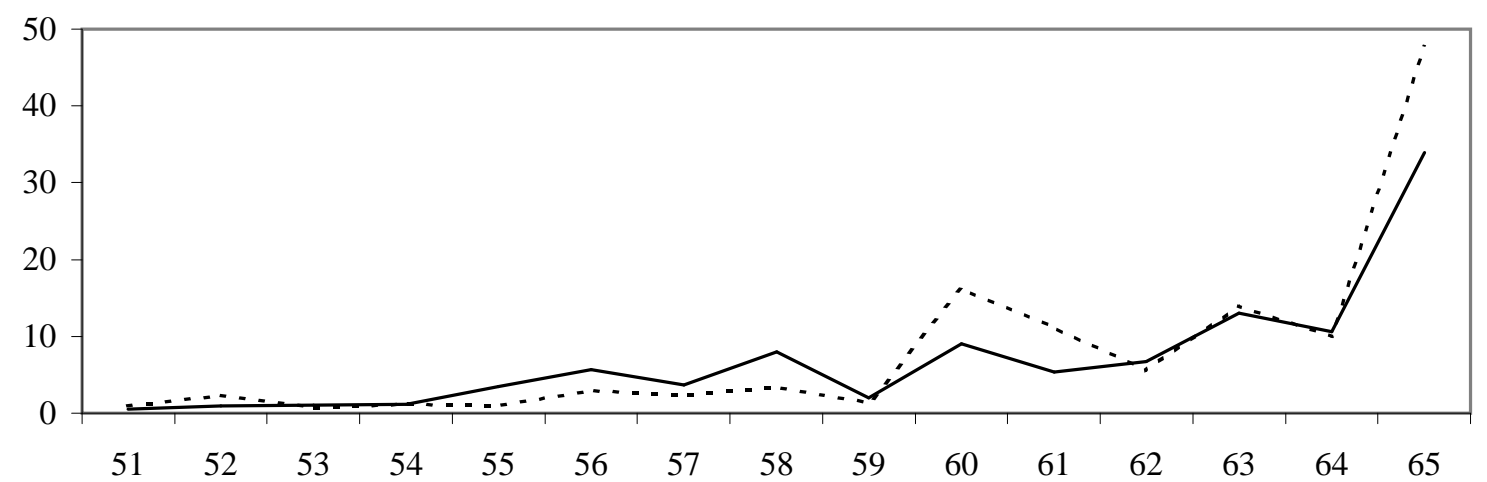

Age

$\%$

Females

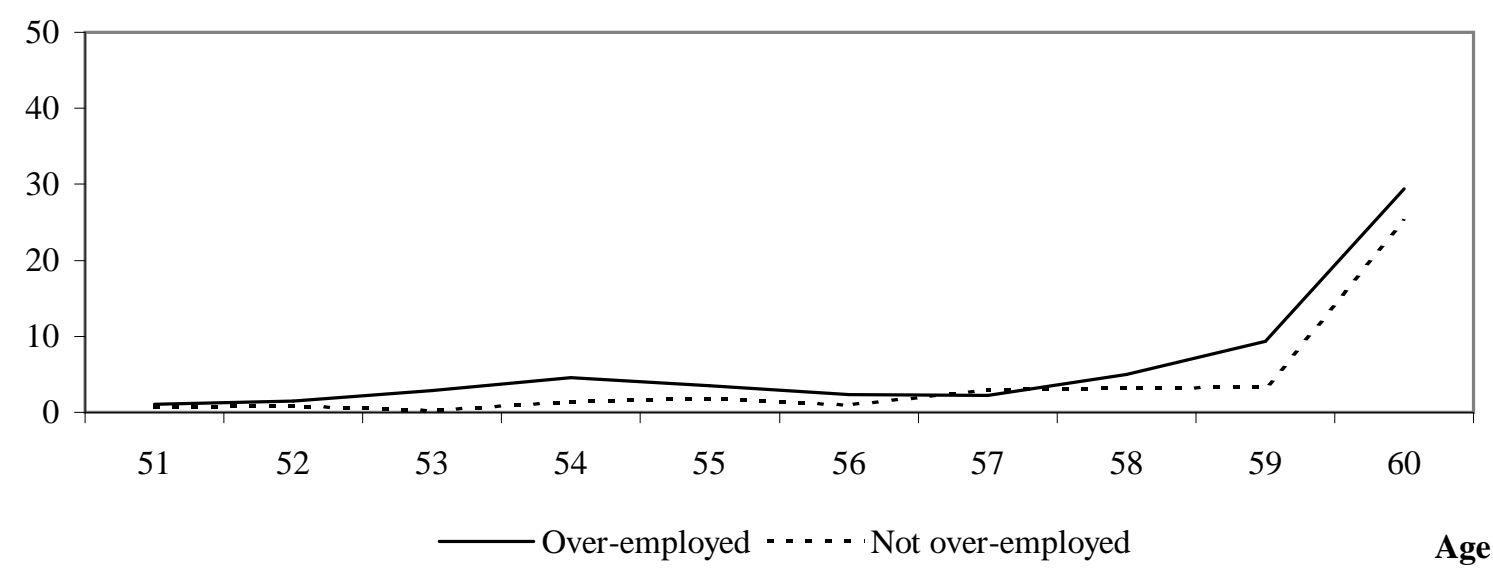


Figure 4: Hazard rate to inactivity

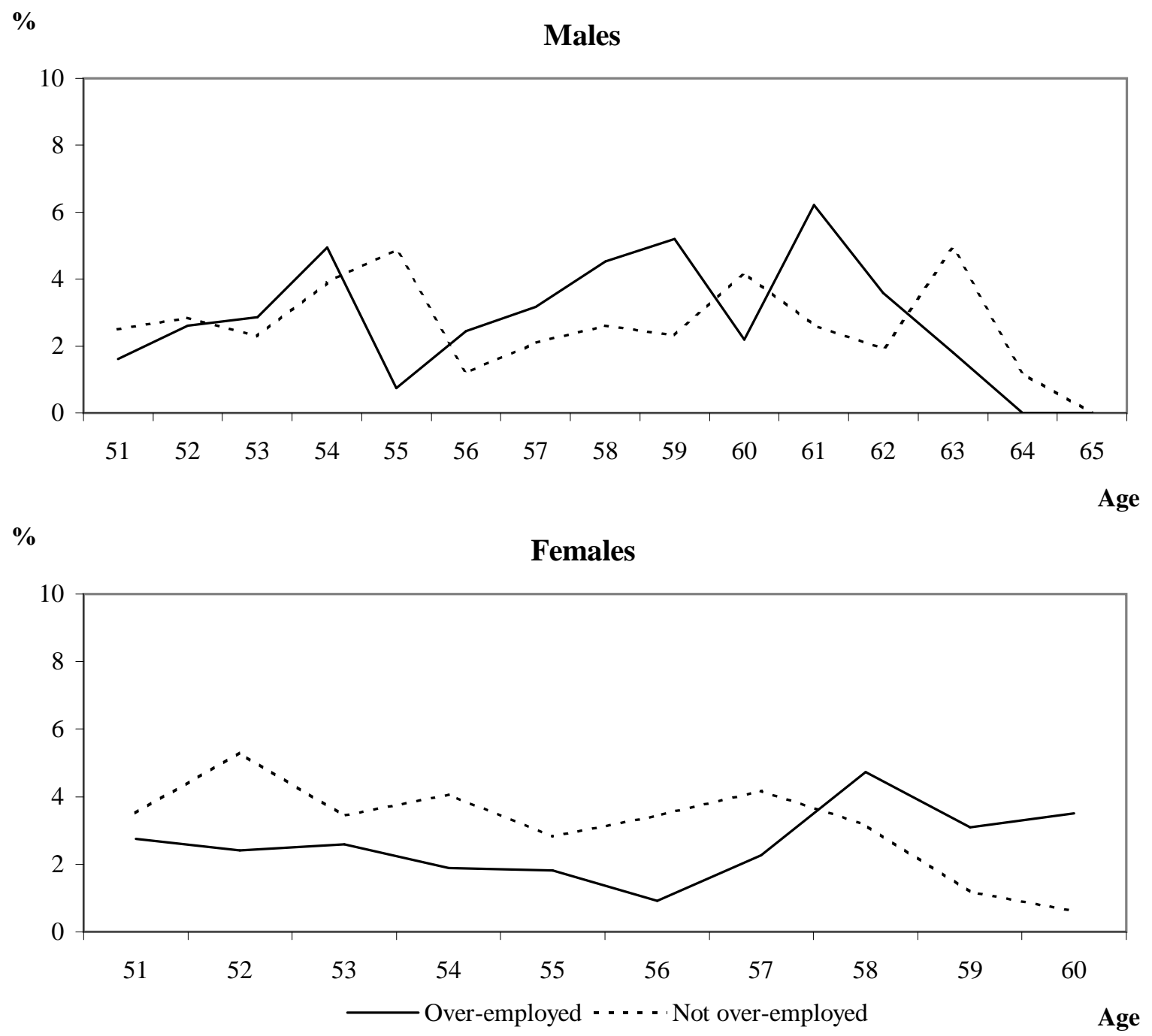


Figure 5: Hazard rate to hours reduction with the employer

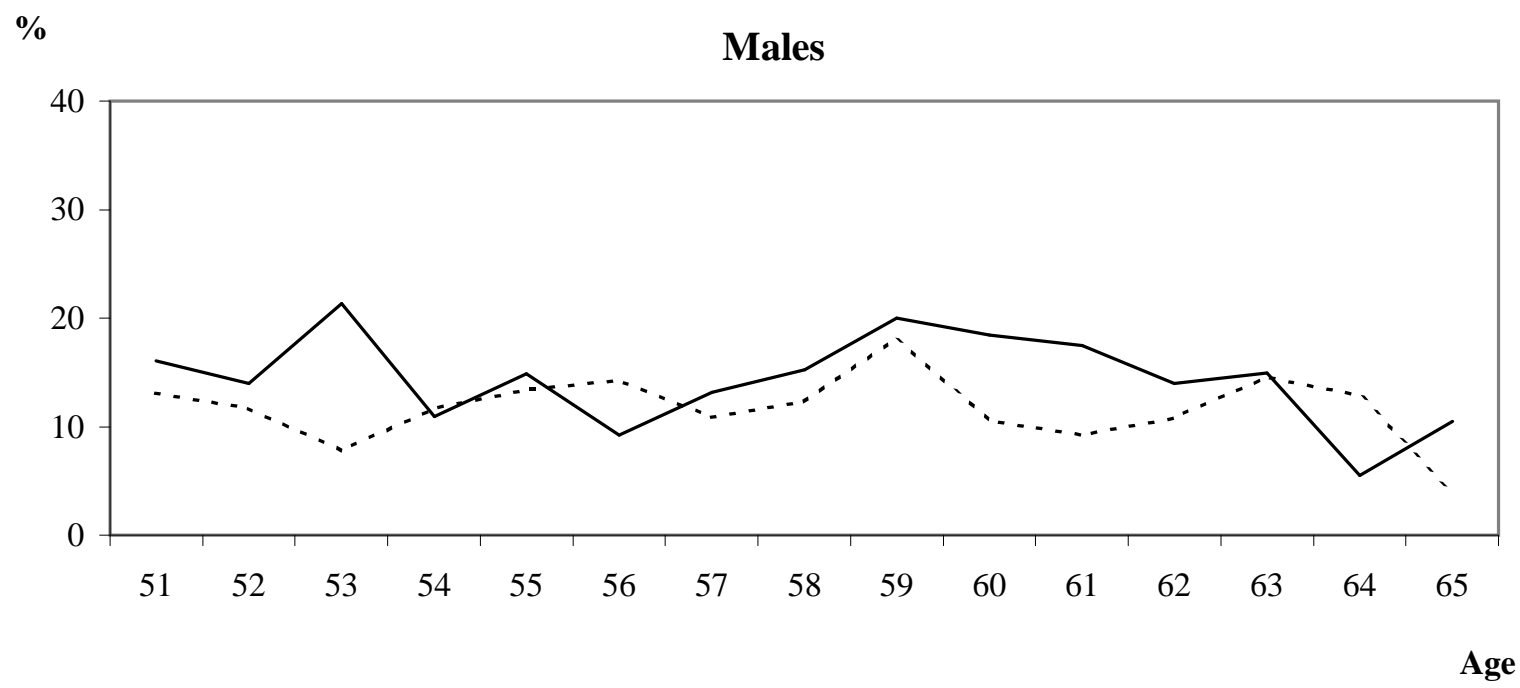

$\%$

Females

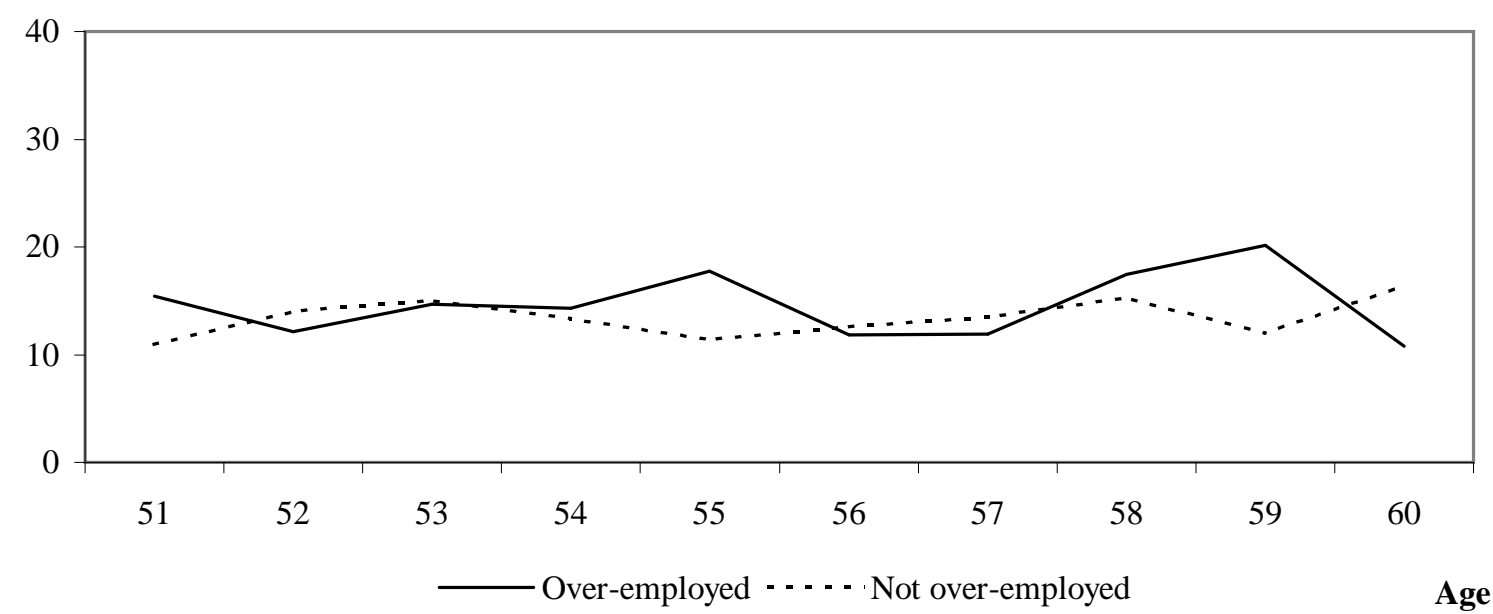


Figure 6: Hazard rate to an employer change (less hours)

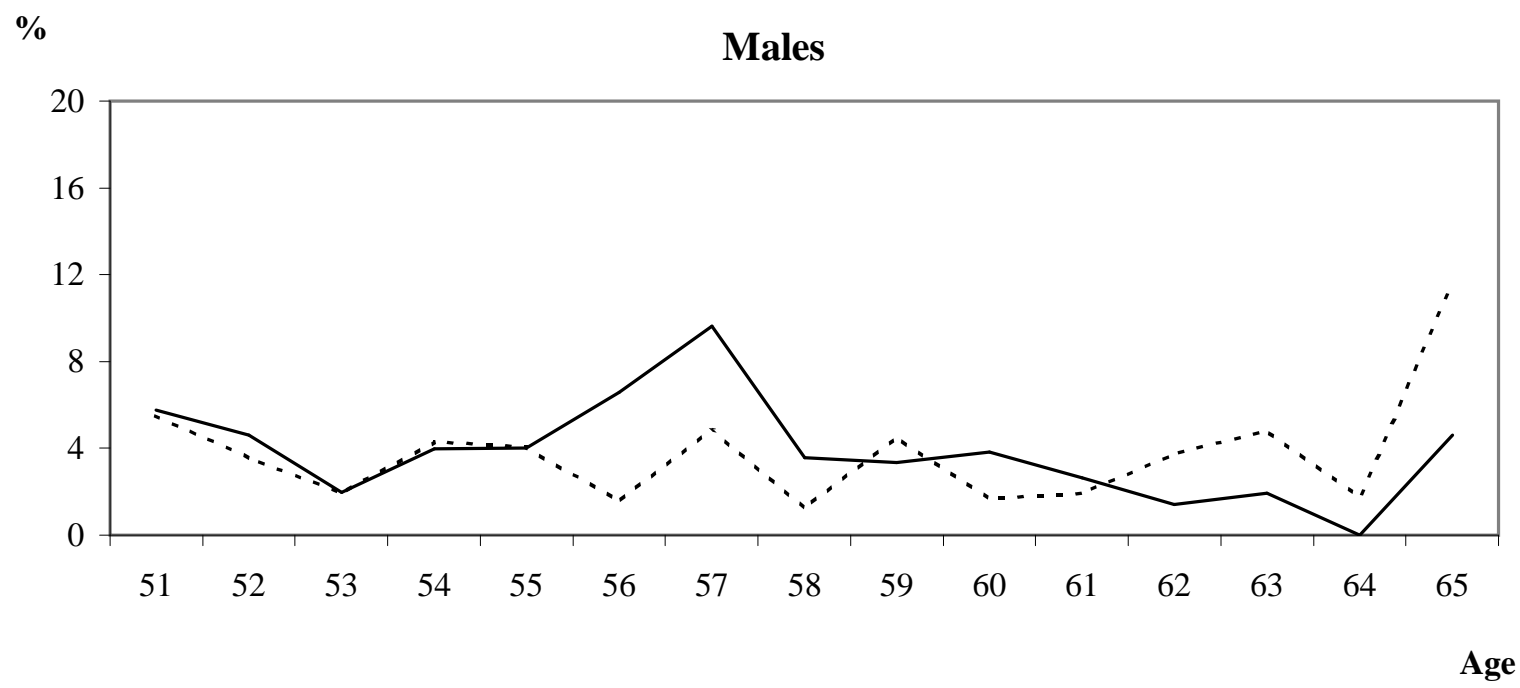

$\%$

Females

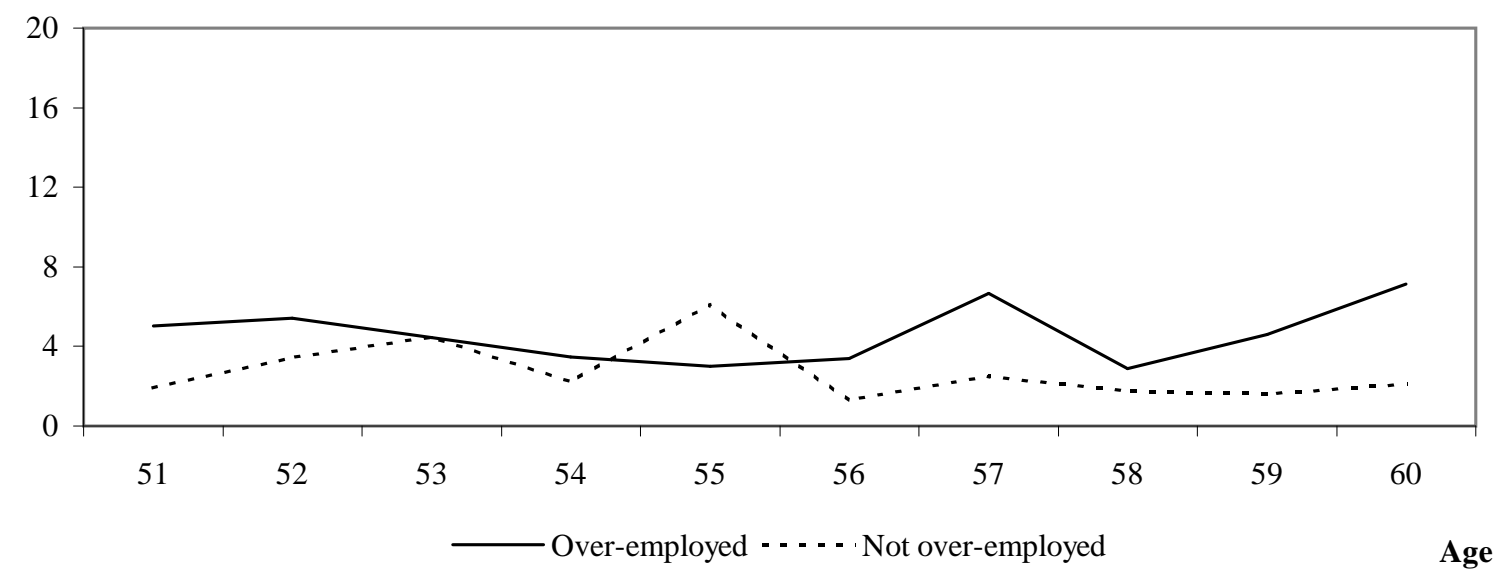


Figure 7: Hazard rate to an employer change (same/more hours)

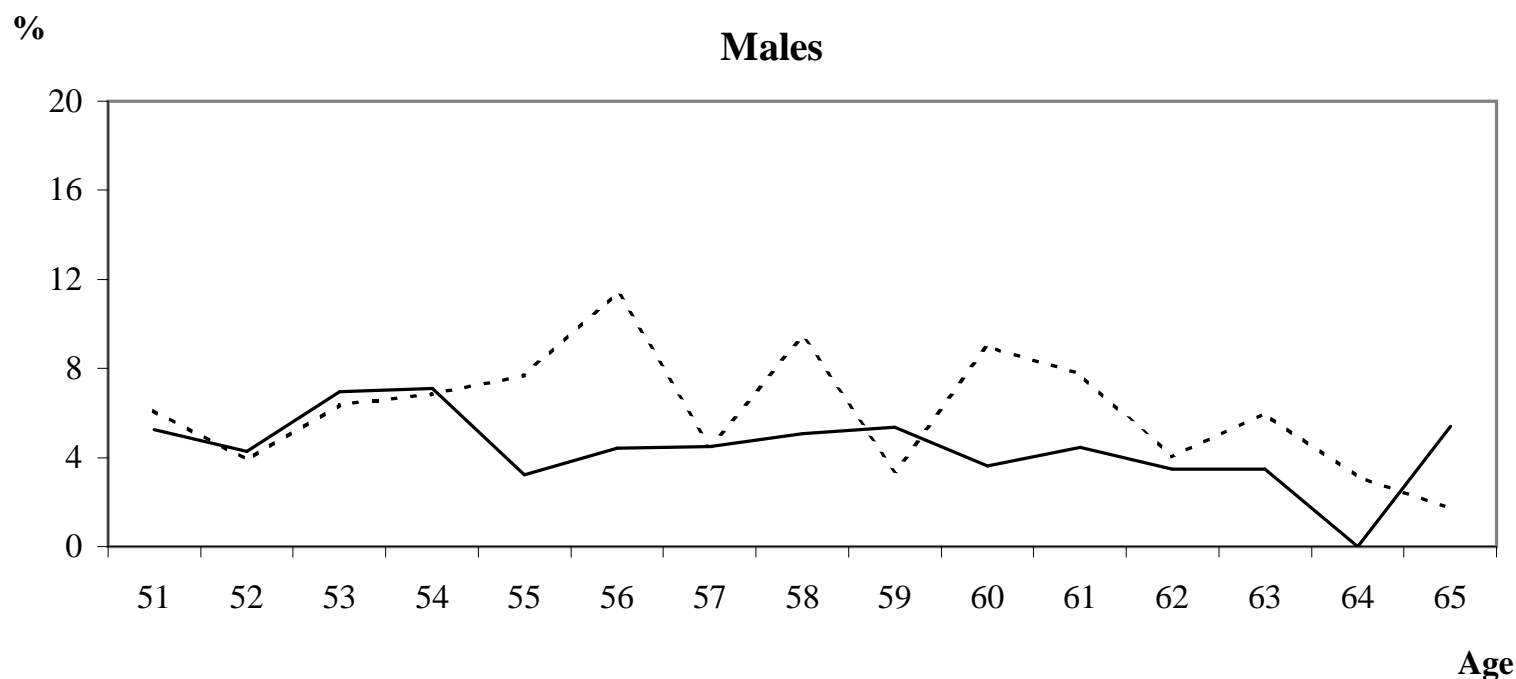

$\%$

Females

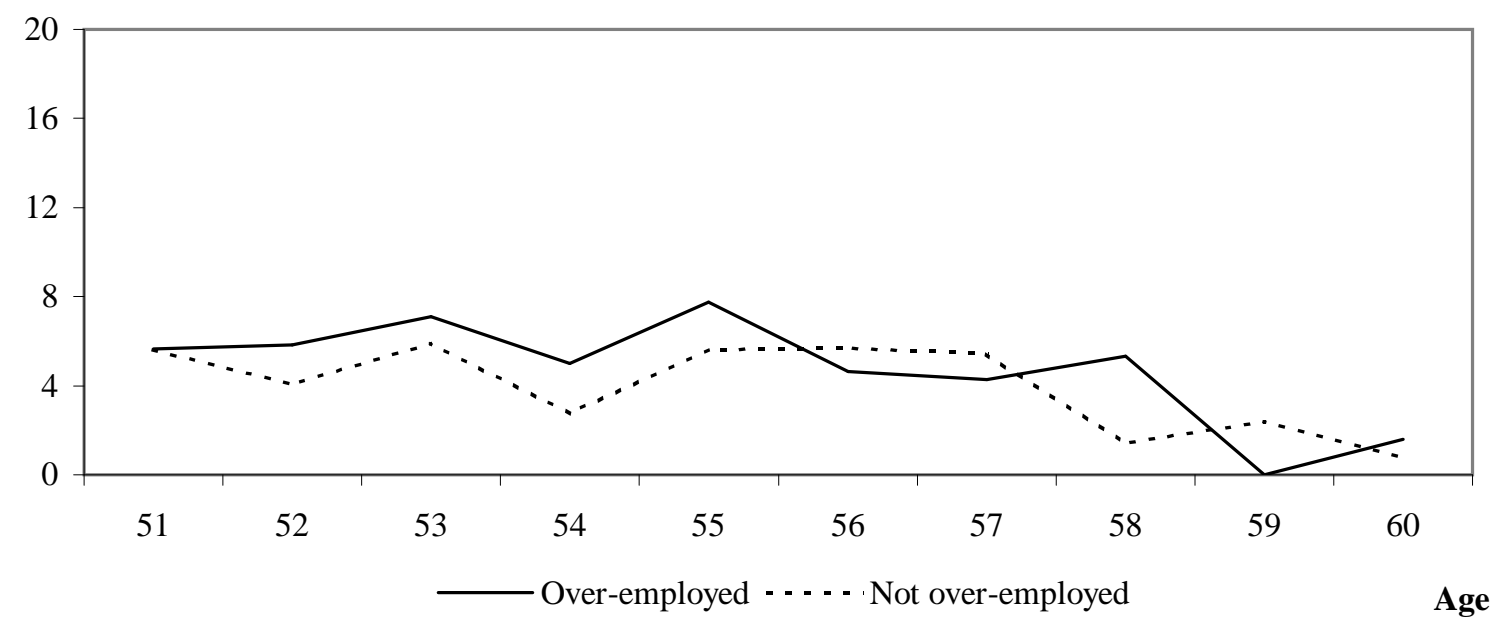


Figure 8: Predicted survivor function

Males

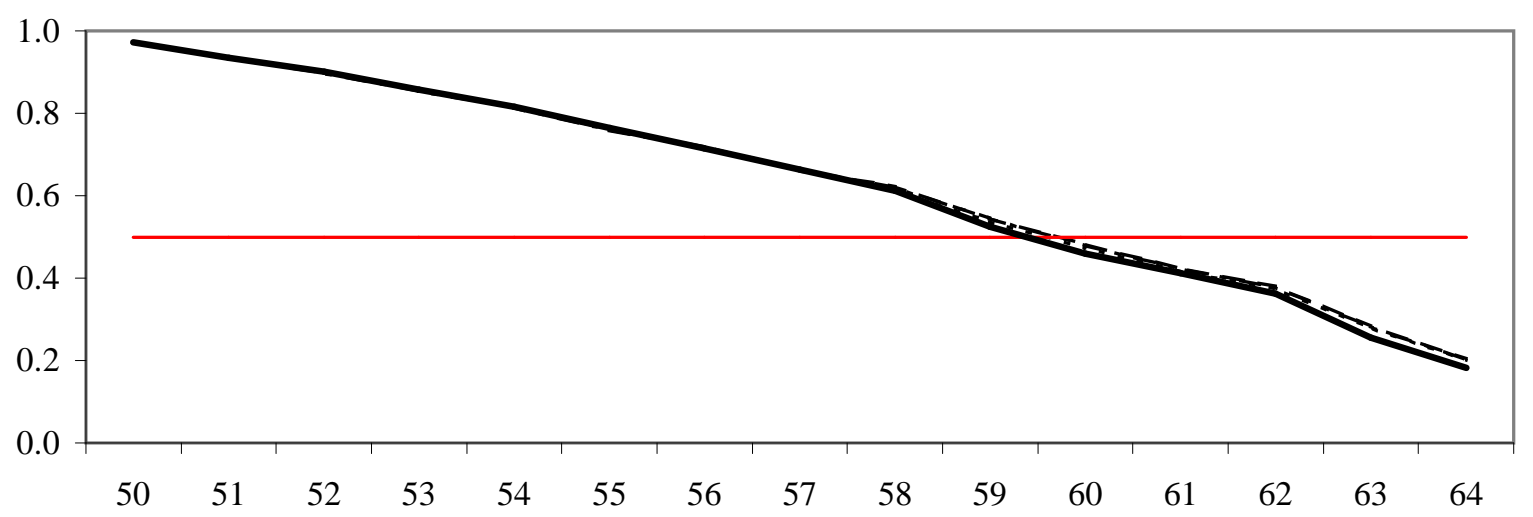

Females

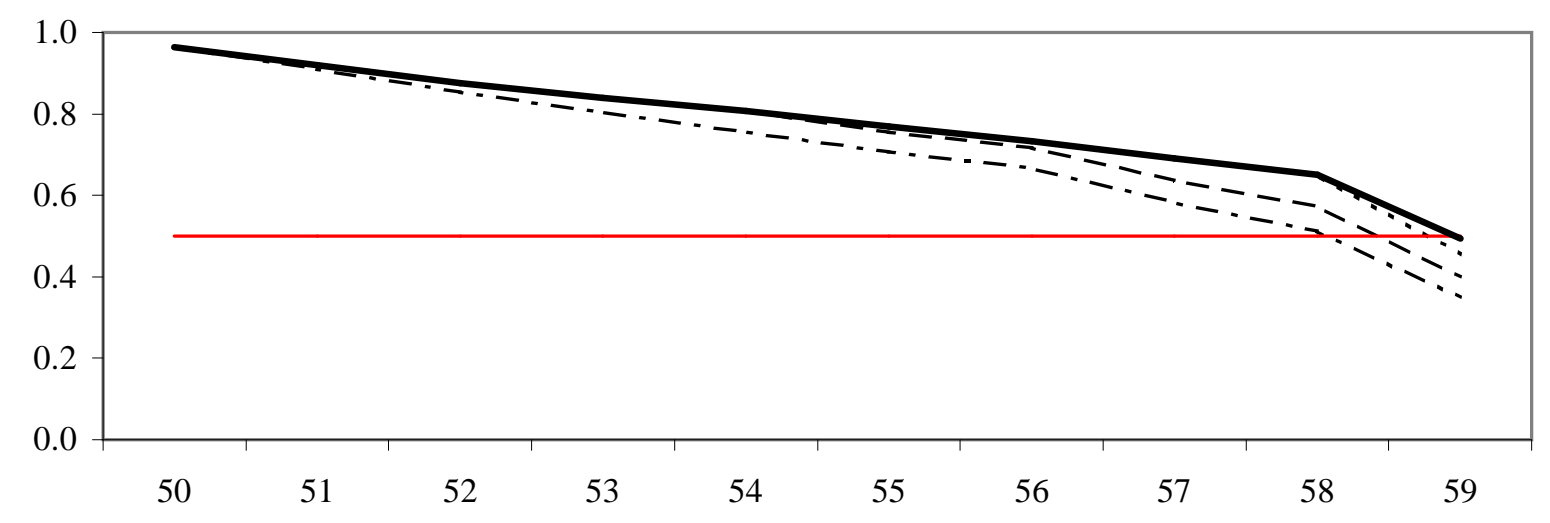

Over-employment as of:

- - - Age 51 - - Age 55 - - . Age $59 \quad$ Not over-employed 
Figure 9: Total number of hours worked (between age 50 and labor market exit)
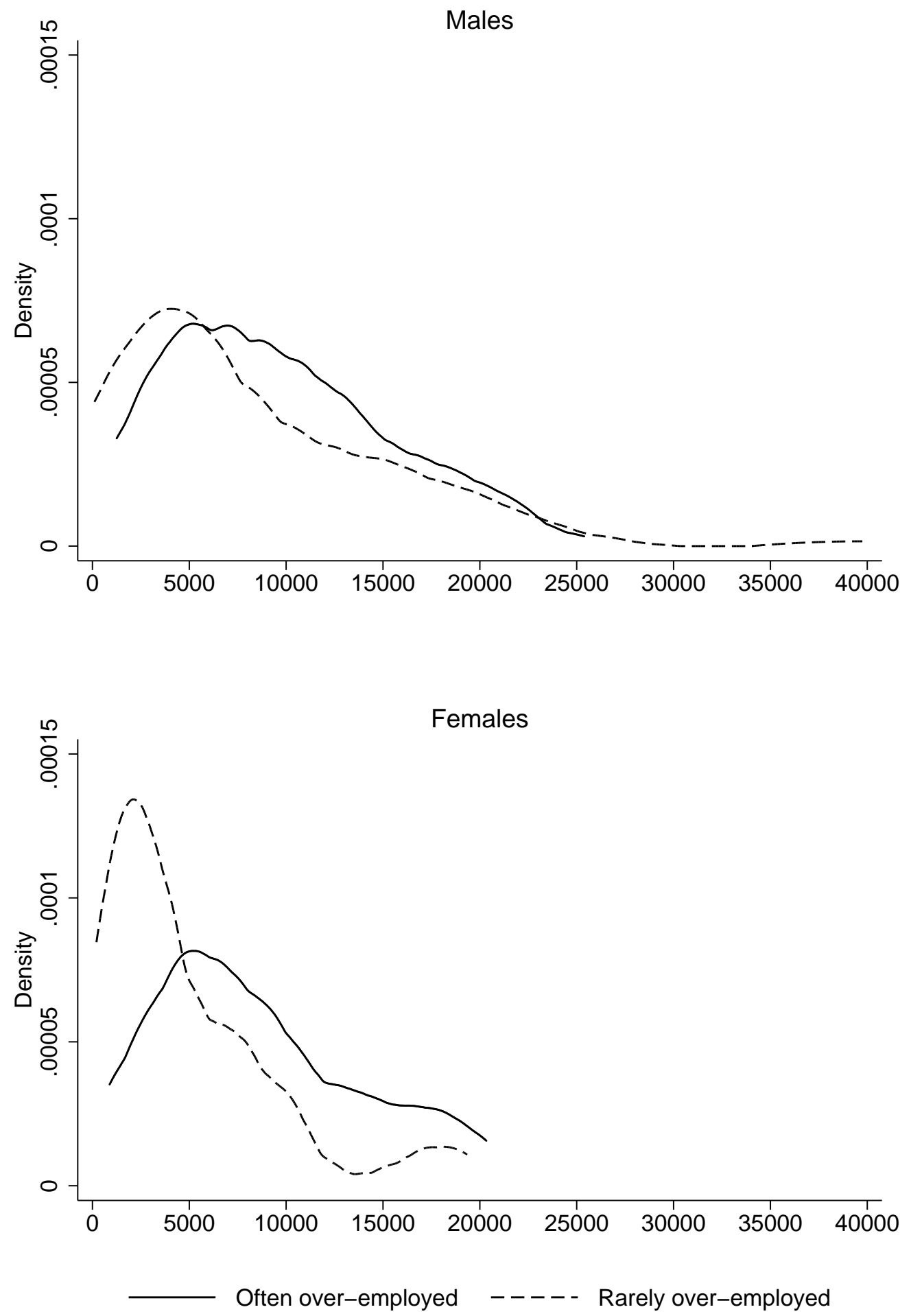


\section{Appendix}

Table A4.1: Relating unobserved to observed heterogeneity

\begin{tabular}{|c|c|c|c|c|c|c|}
\hline & \multicolumn{3}{|c|}{ Males } & \multicolumn{3}{|c|}{ Female } \\
\hline & 1 & 2 & 3 & 1 & 2 & 3 \\
\hline Over-employment & 43.3 & 35.9 & 50.9 & 35.8 & 42.2 & 39.0 \\
\hline Part-time work & 3.9 & 1.9 & 8.2 & 43.8 & 38.6 & 28.5 \\
\hline Unemployment rate & 5.1 & 5.8 & 4.3 & 5.0 & 5.5 & 5.5 \\
\hline Married & 87.9 & 91.7 & 92.7 & 80.3 & 81.1 & 84.2 \\
\hline Tenure (years) & 12.2 & 10.0 & 14.4 & 0.0 & 0.0 & 0.0 \\
\hline Gross hourly wage & 10.1 & 9.4 & 10.7 & 6.9 & 7.6 & 7.5 \\
\hline Temporary job & 53.5 & 42.2 & 44.5 & 55.8 & 46.0 & 33.3 \\
\hline $\begin{array}{l}\text { Member empl. pension scheme } \\
\text { Satisfaction }\end{array}$ & 71.1 & 63.8 & 83.6 & 51.4 & 59.1 & 63.2 \\
\hline Satisfied with pay & 34.3 & 34.3 & 10.9 & 28.2 & 33.5 & 23.7 \\
\hline Satisfied with work itself & 18.1 & 21.0 & 7.3 & 13.1 & 17.3 & 12.3 \\
\hline $\begin{array}{l}\text { Satisfied with job security } \\
\text { Age }\end{array}$ & 28.5 & 34.0 & 17.3 & 18.5 & 22.7 & 14.9 \\
\hline $50-54$ & 54.0 & 38.1 & 36.4 & 64.4 & 59.4 & 48.7 \\
\hline $55-59$ & 31.3 & 42.9 & 38.2 & 35.6 & 40.6 & 51.3 \\
\hline $60-64$ & 14.7 & 19.0 & 25.5 & - & - & - \\
\hline Firm & & & & & & \\
\hline $1-9$ & 15.0 & 21.3 & 17.3 & 21.6 & 15.1 & 23.2 \\
\hline $10-49$ & 24.4 & 21.3 & 10.0 & 36.3 & 37.1 & 34.2 \\
\hline $50-99$ & 12.4 & 20.3 & 9.1 & 9.9 & 11.9 & 10.1 \\
\hline 100-199 & 10.9 & 11.7 & 12.7 & 8.9 & 10.4 & 11.4 \\
\hline $200-499$ & 17.6 & 9.5 & 28.2 & 9.7 & 10.9 & 9.2 \\
\hline $\begin{array}{l}500+ \\
\text { Predicted exit rate }\end{array}$ & 19.6 & 15.9 & 22.7 & 13.6 & 14.6 & 11.8 \\
\hline Retirement & 4.3 & 5.3 & 1.9 & 3.5 & 2.4 & 3.3 \\
\hline Inactivity & 3.0 & 1.8 & 3.2 & 2.5 & 3.8 & 1.7 \\
\hline Hours reduction with employer & 14.1 & 9.0 & 5.5 & 13.7 & 14.0 & 8.8 \\
\hline Hours reduction by changing employer & 4.2 & 1.5 & 4.5 & 3.3 & 5.0 & 3.6 \\
\hline Employer change (same/more hours) & 5.7 & 3.5 & 6.4 & 4.2 & 7.5 & 4.9 \\
\hline $\mathrm{N}$ & 3922 & 654 & 405 & 3128 & 1292 & 509 \\
\hline
\end{tabular}

